FY 2005

\title{
REAL TIME FLUX CONTROL IN PM MOTORS
}

Prepared by:

Oak Ridge National Laboratory

Mitch Olszewski, Program Manager

Submitted to:

Energy Efficiency and Renewable Energy

FreedomCAR and Vehicle Technologies

Vehicle Systems Team

Susan A. Rogers, Technology Development Manager

September 2005 
NATIONAL LABORATORY

MANAGED BY UT-BATTELLE

FOR THE DEPARTMENT OF ENERGY

\title{
Engineering Science \& Technology Division
}

\section{Real Time Flux Control in PM Motors}

\author{
P. J. Otaduy \\ J. W. McKeever
}

Publication Date: September 2005

\author{
Prepared by the \\ OAK RIDGE NATIONAL LABORATORY \\ Oak Ridge, Tennessee 37831 \\ managed by \\ UT-BATTELLE, LLC \\ for the \\ U.S. DEPARTMENT OF ENERGY \\ Under contract DE-AC05-00OR22725
}

บT-BATTELLE

ORNL-27 (4-00) 
This report was prepared as an account of work sponsored by an agency of the United States Government. Neither the United States Government nor any agency thereof, nor any of their employees, makes any warranty, express or implied, or assumes any legal liability or responsibility for the accuracy, completeness, or usefulness of any information, apparatus, product, or process disclosed, or represents that its use would not infringe privately owned rights. Reference herein to any specific commercial product, process, or service by trade name, trademark, manufacturer, or otherwise, does not necessarily constitute or imply its endorsement, recommendation, or favoring by the United States Government or any agency thereof. The views and opinions of authors expressed herein do not necessarily state or reflect those of the United States Government or any agency thereof. 


\section{Page}

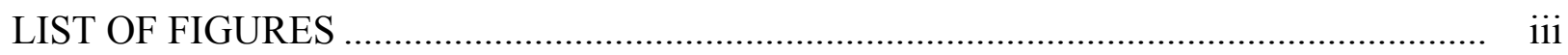

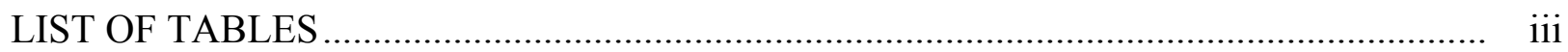

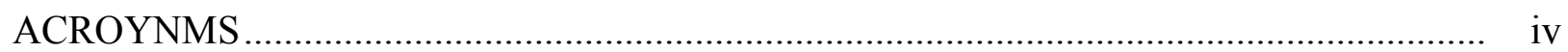

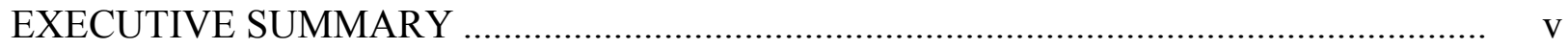

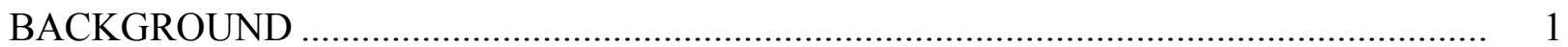

CONCEPTS OF DIRECT-FLUX CONTROL .................................................................. 2

METHODS OF DIRECT-FLUX CONTROL ……………..............................................

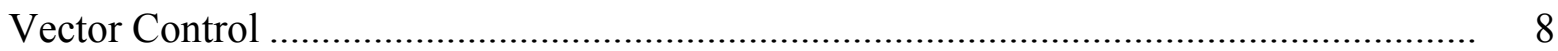

Flux Weakening in Consequent Pole Generator................................................................ 8

High-Strength Undiffused Brushless PM Motor ................................................................ 8

Magnetic Polarization Variation - Memory Motors.......................................................... 9

Magnetic Strength Variation - Thermal Field Weakening ............................................. 10

Changing Number of Stator Turns per Coil.................................................................. 11

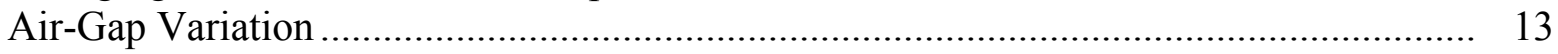

APPROACH FOR DETERMINING FLUX-WEAKENING REQUIREMENTS ................. 14

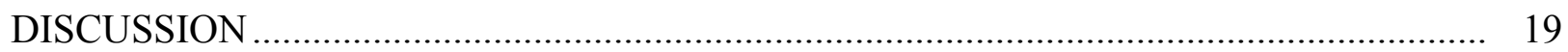

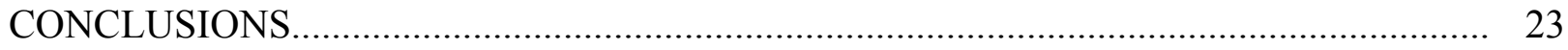

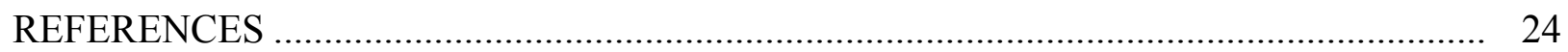

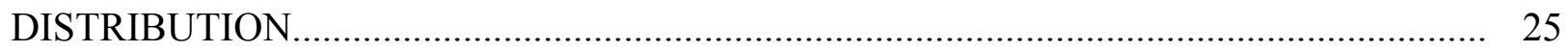




\section{LIST OF FIGURES}

Figure

Page

1 Axial-gap consequent pole generator weakened and strengthened by external coil ..... 8

2 High-strength (magnetic) undiffused brushless axial-gap PM motor ......................... 9

$3 \quad$ Variable flux PM motor - Memory Motor ......................................................... 10

4 Field weakening reflected by lower d-axis current component of total phase current as magnet temperature rises................................................................. 11

5 Using the number of turns per slot to control constant power speed ratio (CPSR)

(a) Performance curve dependency on number of turns..................................... 12

(b) Extending CPSR by reducing the number of turns ..................................... 12

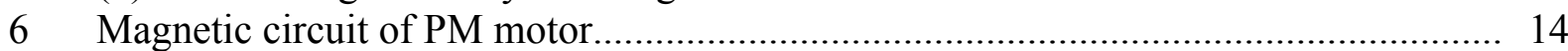

7 Magnetic circuit of a consequent pole PM motor with the same MMFs and reluctances of the motor in Fig. 6 .................................................................... 15

8 Magnet circuit of a consequent pole PM motor in Fig. 7 with the addition of of an externally controlled MMF. 16

9 Equivalent circuit schematics of the $\mathrm{d}$ and q electromagnetic circuits in a PM motor

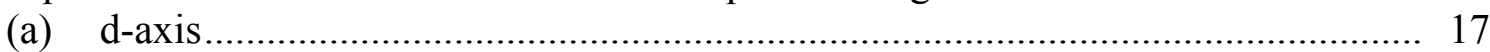

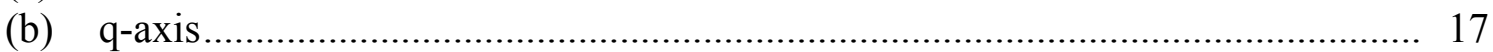

10 Standard electric and magnetic phasor diagrams of a PM motor with $\mathrm{I}_{\mathrm{d}}$ negative ....... 17

\section{LIST OF TABLES}

Table

1 Comparison of RTFC methods for synchronous PM motors with torque and speed control 


\section{ACRONYMS}

CPSR

d-axis

dc

DSP

emf

HEV

IPM

MMF

ORNL

PEEMRC

PM

PWM

q-axis

RTFC constant power speed ratio direct-axis direct current digital signal processor electromotive force hybrid electric vehicle interior permanent magnet magneto-motive force Oak Ridge National Laboratory Power Electronics and Electric Machinery Research Center permanent magnet pulse width modulation quadrature-axis real time flux control 


\section{EXECUTIVE SUMMARY}

Significant research at the Oak Ridge National Laboratory (ORNL) Power Electronics and Electric Machinery Research Center (PEEMRC) is being conducted to develop ways to increase (1) torque, (2) speed range, and (3) efficiency of traction electric motors for hybrid electric vehicles (HEV) within existing current and voltage bounds. Current is limited by the inverter semiconductor devices' capability and voltage is limited by the stator wire insulation's ability to withstand the maximum back-electromotive force (emf), which occurs at the upper end of the speed range.

One research track has been to explore ways to control the path and magnitude of magnetic flux while the motor is operating. The phrase, real time flux control (RTFC), refers to this mode of operation in which system parameters are changed while the motor is operating to improve its performance and speed range. RTFC has potential to meet an increased torque demand by introducing additional flux through the main air gap from an external source. It can augment the speed range by diverting flux away from the main air gap to reduce back-emf at high speeds. Conventional RTFC technology is known as vector control [1]. Vector control decomposes the stator current into two components; one that produces torque and a second that opposes (weakens) the magnetic field generated by the rotor, thereby requiring more overall stator current and reducing the efficiency. Efficiency can be improved by selecting a RTFC method that reduces the back-emf without increasing the average current. This favors methods that use pulse currents or very low currents to achieve field weakening.

Foremost in ORNL's effort to develop flux control is the work of J. S. Hsu. Early research $[2,3]$ introduced direct control of air-gap flux in permanent magnet (PM) machines and demonstrated it with a flux-controlled generator. The configuration eliminates the problem of demagnetization because it diverts all the flux from the magnets instead of trying to oppose it. It is robust and could be particularly useful for PM generators and electric vehicle drives. Recent efforts have introduced a brushless machine that transfers a magneto-motive force (MMF) generated by a stationary excitation coil to the rotor [4]. Although a conventional PM machine may be field weakened using vector control, the air-gap flux density cannot be effectively enhanced. In Hsu's new machine, the magnetic field generated by the rotor's PM may be augmented by the field from the stationery excitation coil and channeled with flux guides to its desired destination to enhance the air-gap flux that produces torque. The magnetic field can also be weakened by reversing the current in the stationary excitation winding. A patent for advanced technology in this area is pending.

Several additional RTFC methods have been discussed in open literature. These include methods of changing the number of poles by magnetizing and demagnetizing the magnets' poles with pulses of current corresponding to direct-axis (d-axis) current of vector control $[5,6]$, changing the number of stator coils [7], and controlling the air gap [8]. Test experience has shown that the magnet strengths may vary and weaken naturally as rotor temperature increases suggesting that careful control of the rotor temperature, which is no easy task, could yield another method of RTFC. 
The purpose of this report is to (1) examine the interaction of rotor and stator flux with regard to RTFC, (2) review and summarize the status of RTFC technology, and (3) compare and evaluate methods for RTFC with respect to maturity, advantages and limitations, deployment difficulty and relative complexity. 


\section{BACKGROUND}

Electric motors convert electrical energy into mechanical energy using magnetic energy as an intermediary. The electrical energy is first converted to magnetic energy and then transferred through the air gap and converted to mechanical energy in the rotor. According to the energy conservation principle, the instantaneous power input, $p_{i n}$, must equal power losses, $p_{\text {loss, }}$ plus mechanical power output, $p_{\text {mech, }}$ plus change in energy stored internally, which in this case is magnetic power, $\mathrm{p}_{\mathrm{mag}}$, leading to the equation

$$
\mathrm{p}_{\mathrm{mech}}=\mathrm{p}_{\mathrm{in}}-\mathrm{p}_{\text {loss }}-\mathrm{p}_{\mathrm{mag}}
$$

In motors operating under steady state conditions, the stored energy, which is stored power averaged over time, does not change; thus the torque and mechanical power output depend only on the power input and the power losses in the conversion process

$$
\mathrm{P}_{\text {mech }}=\mathrm{P}_{\text {in }}-\mathrm{P}_{\text {loss }}
$$

Consequently, design and performance enhancement efforts attempt to increase or maintain the power input, $\mathrm{P}_{\mathrm{in}}$, capability and minimize the power losses, $\mathrm{P}_{\text {loss, }}$ over the range of operating speeds.

In rotary motors the mechanical power, $\mathrm{P}_{\text {mech }}$, is the product of torque, $\mathrm{T}$, and angular speed, $\omega$,

$$
\mathrm{P}_{\mathrm{mech}}=\mathrm{T} \omega
$$

where

$$
\omega=\mathrm{d} \theta_{\mathrm{m}} / \mathrm{dt} \text { and } \theta_{\mathrm{m}} \text { is the rotor's angular position. }
$$

The torque is produced by the interaction across the air gap of two magnetic fields; one generated in the rotor, $\phi_{\mathrm{r}}$, and the other in the stator, $\phi_{\mathrm{s}}$. The magnitude of the torque is proportional to the product of the magnitudes of the two interacting magnetic fields,

$$
\mathrm{T}=\alpha_{\mathrm{sr}} \phi_{\mathrm{s}} \phi_{\mathrm{r}}
$$

where

$\alpha_{\mathrm{sr}}$ is the magnetic coupling factor.

This factor depends on the degree of non-alignment between the two magnetic fluxes.

Since the stator's magnetic flux, $\phi_{\mathrm{s}}$, is generally produced by an electrical current, $\mathrm{I}_{\mathrm{s}}$, it is common to express the torque in terms of the current and the rotor's flux, as follows

$$
\mathrm{T}=\alpha^{*}{ }_{\mathrm{sr}} \mathrm{I}_{\mathrm{s}} \phi_{\mathrm{r}},
$$


where the new coupling term, $\alpha_{\text {sr }}^{*}$, now incorporates the proportionality between $I_{s}$ and $\phi_{\mathrm{s}}$.

\section{CONCEPTS OF DIRECT-FLUX CONTROL}

In PM machines, the rotor's magnetic field is produced by its built-in PMs and by magnetic poles induced by the stator-generated magnetic field on the rotor's iron-surface boundaries adjacent to the air gap. The rotor flux, $\phi_{\mathrm{r}}$, is the flux that flows when there are no other sources of magnetic energy other than those in the rotor.

The stator magnetic field is produced by electric currents circulating through electric conductors, which are usually made of copper and embedded in the stator. It is the nature of electrical currents to generate magnetic fields around them. The magnitude of a magnetic field produced depends on the strength of the MMF as well as on the distribution of reluctance, $\boldsymbol{R}$, along the path followed by the magnetic field. Magnetic fields follow closed paths. The MMF equals the total amount of current carried by $\mathrm{N}$ conductors. When all $\mathrm{N}$ conductors carry the same current, $\mathrm{i}, \mathrm{MMF}=\mathrm{Ni}$ and it plays the same role that a voltage source plays in an electric circuit. Reluctance is a property used in magnetic circuits that accounts for the geometric length-to-area ratio, $\ell / A$, and magnetic permeability, $\mu$, of a medium in which the magnetic flux flows

$$
R=\ell /(\mu A) .
$$

Reluctance can be viewed as the resistance to the flow of magnetic flux. The stator flux, $\phi_{\mathrm{s}}$, is the flux that would flow when there are no other sources of magnetic energy than current flowing in the wires of the stator.

In reality the stator and rotor magnetic fluxes are not physically distinct but combine into an overall flux, $\phi$, that follows a closed path from the magnet pole through the air gap, stator, air gap, opposite magnet pole, and back through the rotor to the original pole. From Ampere's circuital law, the total magnetic flux in a circuit driven by a total MMF of magnitude, $\mathscr{F}_{t}$, is given by the ratio

$$
\phi=\mathscr{F}_{\mathrm{t}} / \boldsymbol{R}_{\mathrm{t}},
$$

where

$\boldsymbol{R}_{\mathrm{t}}$ is the overall reluctance of the magnetic circuit.

Then, as shown below, the torque is proportional to the square of the total flux

and

$$
\mathrm{T}=\mathrm{A}_{\mathrm{sr}} \phi^{2},
$$

$$
\mathrm{A}_{\mathrm{sr}}=\alpha_{\mathrm{sr}}\left(1-\kappa_{\mathrm{sr}}\right)\left(1-\kappa_{\mathrm{rs}}\right) /\left(1-\kappa^{2}\right)^{2},
$$


is the new coupling coefficient where

$\kappa_{\mathrm{sr}}$ is the fraction of rotor flux that couples with the stator,

$\kappa_{\mathrm{rs}}$ is the fraction of stator flux that couples with the rotor, and

$\kappa=\left(\kappa_{\mathrm{sr}} \kappa_{\mathrm{rs}}\right)^{1 / 2}$.

This coefficient depends on the degree of mirror asymmetry between the paths of the magnetic flux entering and exiting the air gap. It is most useful to look at the magnetic-flux lines crossing the air gap as if they were stretched out rubber bands anchored at the stator and rotor connecting points. The flux would be the number of rubber bands. The farther stretched out the more energy the rubber bands store and the stronger their pull. Only the tangential component of the force on the rotor contributes to the torque and power output. The sum of all the tangential rubber band forces determines the direction and magnitude of the torque.

Equation (7) is derived from Eq. (4) using the flux continuity relationships

$$
\phi=\phi_{\mathrm{s}}+\kappa_{\mathrm{sr}} \phi_{\mathrm{r}}=\phi_{\mathrm{r}}+\kappa_{\mathrm{rS}} \phi_{\mathrm{s}} .
$$

The coefficients in Eq. (7a) can be expressed in terms of the electrical parameters, which are self inductances, $\mathcal{L}_{\mathrm{r}}$ and $\mathcal{L}_{\mathrm{s}}$, mutual inductance, $\mathcal{M}$, and the number of turns in the stator, $\mathrm{N}_{\mathrm{s}}$, and rotor, $\mathrm{N}_{\mathrm{r}}$, as

$$
\begin{aligned}
\mathrm{a} & =\mathrm{N}_{\mathrm{s}} / \mathrm{N}_{\mathrm{r}}, \\
\kappa_{\mathrm{s}} & =\boldsymbol{M} /\left(\mathrm{a} \mathcal{L}_{\mathrm{r}}\right), \text { and } \\
\kappa_{\mathrm{s}} & =\mathrm{a} \boldsymbol{M} / \mathcal{L}_{\mathrm{s}},
\end{aligned}
$$

where

$\mathcal{L}_{\mathrm{s}}=\mathrm{N}_{\mathrm{s}} \phi_{\mathrm{s}} / \mathrm{I}_{\mathrm{s}}$ is the stator's self inductance,

$\mathcal{L}_{\mathrm{r}}=\mathrm{N}_{\mathrm{r}} \phi_{\mathrm{r}} / I_{\mathrm{r}}$ is the rotor's self inductance, and

$\boldsymbol{M}=\mathrm{N}_{\mathrm{s}} \kappa_{\mathrm{sr}} \phi_{\mathrm{r}} / \mathrm{I}_{\mathrm{r}}=\mathrm{N}_{\mathrm{r}} \kappa_{\mathrm{rs}} \phi_{\mathrm{s}} / \mathrm{I}_{\mathrm{s}}$ is the stator-rotor mutual inductance.

Considering that

$\mathcal{F}_{\mathrm{s}}=\mathrm{N}_{\mathrm{s}} \mathrm{I}_{\mathrm{s}}$ represents the stator's MMF, and

$\mathscr{F}_{\mathrm{r}}=\mathrm{N}_{\mathrm{r}} \mathrm{I}_{\mathrm{r}}$ represents the rotor's MMF

allows us to express the electric self inductance in terms of their corresponding magnetic parameters:

$$
\begin{aligned}
& \mathcal{L}_{\mathrm{s}}=\mathrm{N}_{\mathrm{s}} \phi_{\mathrm{s}} / \mathrm{I}_{\mathrm{s}}=\mathrm{N}_{\mathrm{s}}{ }^{2} \phi_{\mathrm{s}} / \mathcal{F}_{\mathrm{s}}=\mathrm{N}_{\mathrm{s}}{ }^{2} / \boldsymbol{R}_{\mathrm{s}}, \\
& \mathcal{L}_{\mathrm{r}}=\mathrm{N}_{\mathrm{r}} \phi_{\mathrm{r}} / \mathrm{I}_{\mathrm{r}}=\mathrm{N}_{\mathrm{r}}{ }^{2} \phi_{\mathrm{r}} / \mathscr{F}_{\mathrm{r}}=\mathrm{N}_{\mathrm{r}}{ }^{2} / \mathscr{R}_{\mathrm{r}} .
\end{aligned}
$$

PMs are sources of MMF. They are characterized by their remanence, $\mathrm{B}_{\mathrm{r}}$, and their magnetic permeability, $\mu_{\mathrm{m}}$. $\mathrm{B}_{\mathrm{r}}$ is the magnetic-flux density the PM produces when its poles are shorted by 
an external material of zero reluctance. Then the reluctance of the magnetic circuit is equal to the PM's internal reluctance; consequently, the MMF produced by a PM is proportional to its $\mathrm{B}_{\mathrm{r}}$ and its length as

$$
\mathcal{F}_{\mathrm{m}}=\phi_{\mathrm{mr}} \boldsymbol{R}_{\mathrm{m}}=\left(\mathrm{B}_{\mathrm{r}} \boldsymbol{A}_{\mathrm{m}}\right) 1_{\mathrm{m}} /\left(\boldsymbol{A}_{\mathrm{m}} \mu_{\mathrm{m}}\right)=\mathrm{B}_{\mathrm{r}} 1_{\mathrm{m}} /\left(\mu_{\mathrm{r}} \mu_{\mathrm{o}}\right)
$$

where
$\mathcal{F}_{\mathrm{m}}$ is the magnet's MMF,
$\phi_{\mathrm{mr}}$ is the magnet's flux remanence,
$\boldsymbol{R}_{\mathrm{m}}$ is the magnet's reluctance,
$\mathrm{B}_{\mathrm{r}}$ is the magnet's flux density remanence,
$A_{\mathrm{m}}$ is the magnet's cross sectional area,
$1_{\mathrm{m}}$ is the magnet's length,
$\mu_{\mathrm{m}}$ is the magnet's permeability
$\mu_{\mathrm{r}}$ is the magnet's relative permeability, $\mu_{\mathrm{m}} / \mu_{\mathrm{o}}$ and
$\mu_{\mathrm{o}}$ is the permeability of vacuum $=4 \pi 10^{-7} \mathrm{H} / \mathrm{m}$.

Design and performance optimization efforts focus on enhancing the contributions of one or more of the parameters in the groups: $\left[\phi_{\mathrm{s}}, \phi_{\mathrm{r}}, \kappa_{\mathrm{sr}}\right],\left[\phi, \boldsymbol{\mathcal { R }}_{\mathrm{t}}\right],\left[\boldsymbol{L}_{\mathrm{r}}, \boldsymbol{L}_{\mathrm{s}}, \boldsymbol{M}, \boldsymbol{F}_{\mathrm{s}}, \mathcal{F}_{\mathrm{r}}\right]$, and $\left[\phi, \mathcal{F}_{\mathrm{t}}\right]$; thus, understanding the dependencies between these parameters is essential.

To put into perspective the relative magnitudes of the stator and rotor magnetic strengths, consider the number of ampere-turns needed to produce the same amount of MMF produced by a PM. For a typical $5 \mathrm{~mm}$ Neodymium PM (characterized by $\mathrm{B}_{\mathrm{r}}=1.12 \mathrm{~T}$ and $\mu_{\mathrm{r}}=1.1$ ), the MMF is $\mathcal{F}_{\mathrm{m}}=4051 \mathrm{~A}$, which is large. To match this $\mathrm{MMF}$, the current and number of conductors needed would be $4000 \mathrm{~A}$ in a one turn, $400 \mathrm{~A}$ with 10 turns, or $40 \mathrm{~A}$ with 100 turns. In addition, the reluctance of the rotor flux is normally lower or equal to that for the stator flux depending on the rotational magnetic uniformity of the rotor.

To obtain the maximum magnetic flux out of the available MMF, most designs reduce the total reluctance by making the stators with iron whose magnetic permeability is thousands of times higher than the permeability of air. The iron has slots filled with copper conductors and teeth to carry the magnetic field to the air-gap surface. Thus, the magnetic flux follows a path comprising lengths of iron, air, copper, and PM materials in which most of the MMF losses occur in the noniron segments. The stator iron can thus be seen as a magnetic dipole effectively piping the MMF from the point of generation to the surface of the air gap with little losses.

It should be noted that because of the high permeability (low reluctance) of the stator iron and the air-like permeability of copper, the magnetic flux in the stator flows mostly inside the iron. Little of the magnetic flux generated by the rotor ever crosses the copper conductors in the stator slots. The main force is generated at the air gap by the interaction between the magnetic dipoles induced in the stator's iron and the rotor, not at the conductors. 
Were the permeability of the stator's iron to be infinite then the magnetic-flux density in the conductors would be zero, but the force would remain. It would even increase slightly because of the reduced contribution of the iron to the total reluctance. In view of the Lorentz force law, force generation in the absence of magnetic flux crossing the main conductors seems paradoxical. But in the presence of ferromagnetic materials when applying Lorentz's law, one needs to consider the equivalent currents induced in magnetic materials by the magnetic flux. When magnetic materials are involved, it is more intuitive to use energy balances or inductance coupling and Faraday's law of induction for changing magnetic fields. The emf, $e$, induced in a conductor is proportional to the integral of the rate of change of magnetic potential along the conductor

$$
e=-\oint_{L} d A / d t \bullet d l
$$

where

$A$ is the magnetic potential, defined so that $B=\operatorname{curl}(A)$, and $\mathrm{L}$ is the length of the conductor.

When the magnetic-flux density is zero, $B=\operatorname{curl}(\mathbf{A})=0$, which does not necessarily mean that the magnetic potential, $\mathbf{A}$, or its divergence, or its time derivative are zero.

Then, replacing $-e$ by $e$ because of sign convention, Eqs. (2) and (3) lead to the torque equation

$$
T=\frac{\left(e i-P_{\text {loss }}\right)}{\omega}=\frac{\left(i \oint_{L} d A / d t \bullet d l-P_{\text {loss }}\right)}{\omega} .
$$

For analyses using finite-element algorithms, it is most practical to solve for the vector potential, A. Unfortunately the vector potential does not embrace a physical meaning and, thus, is not exploited for most engineering design and performance studies. Note, however, that the vector potential has the same direction as the current and, thus, in 2D computations it has only a nonzero $z$-axis component, $\mathbf{A}=\left[0,0, \mathrm{~A}_{\mathrm{z}}\right]$. As a result, $\mathrm{B}=\left[\mathrm{B}_{\mathrm{x}}, \mathrm{B}_{\mathrm{y}}, 0\right]=\operatorname{curl}(\mathbf{A})=\left[\delta \mathrm{A}_{\mathrm{z}} / \delta \mathrm{y},-\delta \mathrm{A}_{\mathrm{z}} / \delta \mathrm{x}\right.$, $0]$ everywhere. This allows for visualization of the magnetic-flux lines, $B$, simply by plotting the contour equipotential lines of $\mathbf{A}$.

It is more traditional to write the emf by using Stokes' theorem in terms of flux linkages as

$$
e=-\oint_{L} d A / d t \bullet d l=-\oint_{S} d(\operatorname{curl}(A)) / d t \bullet d S=-\oint_{S} d B / d t \bullet d S=-d \lambda / d t
$$

with $\lambda=\mathrm{N} \phi$ in case the line integral over length, $\mathrm{L}$, involves more than one turn. These equalities arise because the time derivative may be taken outside of the integrals.

In the case of motors with PMs in the rotor, the main contributor to changes in the magnetic-flux linkage is the rotor. This is obvious under no load conditions where the stator current is zero. Hence, the back-emf fluctuations in a stator conductor are closely linked to the passing of a PM 
under the adjacent stator tooth. The time rate of change of $\lambda$ is thus directly proportional to the rotor's speed. As the speed of magnetic flux changes, both the electrical impedance of the stator conductors and the back-emf generated in them change proportionally (this is discussed later as Eq. (25)). This can be seen with the voltage equation in its instantaneous form

$$
v=i r+e=i r+d \lambda / d t
$$

where $v$ represents the externally applied voltage, $i$ represents the current, $e$ represents the backemf, and $i r$ represents joule heat losses.

Since the value of $e$ depends on the rate of change of the magnetic flux linked, the current and electrical power inputs are then

$$
i=(v-d \lambda / d t) / r
$$

and

$$
p_{\text {in }}=i v=i^{2} r+i e=i^{2} r+i d \lambda / d t
$$

The flux linked can normally be considered a state parameter in the sense that it only depends on the present state, not on how the state was created. Then its dependence on a set of variables, $\left\{\mathrm{x}_{\mathrm{i}}\right\}$, should be considered using the relation

$$
\mathrm{d} \lambda / \mathrm{dt}=\Sigma_{\mathrm{i}}\left(\delta \lambda / \delta \mathrm{x}_{\mathrm{i}}\right) \mathrm{dx} \mathrm{x}_{\mathrm{i}} / \mathrm{dt}
$$

The set of parameters, $\left\{\mathrm{x}_{\mathrm{i}}\right\}$, normally includes the rotor's angular position, $\theta_{\mathrm{m}}$, and stator current, $\mathrm{i}$; but, any other parameter impacting the value of $\lambda$, such as magnet strength, temperature, or current in an additional current loop, should be added. For example, assume the flux linked consists of two main contributions, a current driven contribution and a contribution of magnetic flux, $\phi_{\mathrm{r}}$, originated by the rotor

$$
\lambda=\mathcal{L}_{\mathrm{s}} \mathrm{i}+\mathrm{N}_{\mathrm{s}} \phi_{\mathrm{r}}
$$

so that

$$
\mathrm{d} \lambda / \mathrm{dt}=\mathcal{L}_{\mathrm{s}} \mathrm{di} / \mathrm{dt}+\mathrm{i} \mathrm{d} \boldsymbol{L}_{\mathrm{s}} / \mathrm{dt}+\mathrm{d}\left(\mathrm{N}_{\mathrm{s}} \phi_{\mathrm{r}}\right) / \mathrm{dt}
$$

Also, assume that the PM motor is operating synchronously and the number of rotor poles is fixed so that the current varies with a periodic frequency, $d \theta_{\mathrm{e}} / \mathrm{dt}$, which is proportional to the rotor's speed, $\omega_{\mathrm{m}}$. The constant of proportionality is $v=\theta_{\mathrm{e}} / \theta_{\mathrm{m}}$, which is the ratio of the electrical and mechanical angles and equals the number of pole pairs in the rotor. An electrical cycle occurs as a rotor pole face passes two stator pole faces; consequently, one mechanical cycle of the rotor occurs for every $v$ electrical cycles so that $\mathrm{d} \theta_{\mathrm{e}} / \mathrm{dt}=v \omega_{\mathrm{m}}$. Evaluating the three derivatives on the right of Eq. (20) leads to 


$$
\begin{aligned}
& \mathrm{di} / \mathrm{dt}=\left(\mathrm{di} / \mathrm{d} \theta_{\mathrm{e}}\right) \mathrm{d} \theta_{\mathrm{e}} / \mathrm{dt}=v \omega_{\mathrm{m}}\left(\mathrm{di} / \mathrm{d} \theta_{\mathrm{e}}\right) \\
& \mathrm{d} \boldsymbol{\mathcal { L }}_{\mathrm{s}} / \mathrm{dt}=\left(\mathrm{d} \boldsymbol{\mathcal { L }}_{\mathrm{s}} / \mathrm{d} \theta_{\mathrm{e}}\right) \mathrm{d} \theta_{\mathrm{e}} / \mathrm{dt}=v \omega_{\mathrm{m}}\left(\mathrm{d} \boldsymbol{\mathcal { L }}_{\mathrm{s}} / \mathrm{d} \theta_{\mathrm{e}}\right), \\
& \mathrm{d}\left(\mathrm{N}_{\mathrm{s}} \phi_{\mathrm{r}}\right) / \mathrm{dt}=\mathrm{N}_{\mathrm{s}} \mathrm{d} \phi_{\mathrm{r}} / \mathrm{dt}+\phi_{\mathrm{r}} \mathrm{dN}_{\mathrm{s}} / \mathrm{dt}
\end{aligned}
$$

and

$$
\mathrm{d} \phi_{\mathrm{r}} / \mathrm{dt}=\left(\mathrm{d} \phi_{\mathrm{r}} / \mathrm{d} \theta_{\mathrm{e}}\right) \mathrm{d} \theta_{\mathrm{e}} / \mathrm{dt}=\mathrm{v} \omega_{\mathrm{m}}\left(\mathrm{d} \phi_{\mathrm{r}} / \mathrm{d} \theta_{\mathrm{e}}\right)
$$

which when substituted into Eq. (20) becomes

$$
\mathrm{d} \lambda / \mathrm{dt}=v \omega_{\mathrm{m}}\left[\mathcal{L}_{\mathrm{s}} \mathrm{di} / \mathrm{d} \theta_{\mathrm{e}}+\mathrm{i} \mathrm{d} \mathcal{L}_{\mathrm{s}} / \mathrm{d} \theta_{\mathrm{e}}+\mathrm{N}_{\mathrm{s}}\left(\mathrm{d} \phi_{\mathrm{r}} / \mathrm{d} \theta_{\mathrm{e}}\right)\right]+\phi_{\mathrm{r}} \mathrm{dN} \mathrm{N}_{\mathrm{s}} / \mathrm{dt}
$$

The first three terms on the right in Eq. (25) increase their contribution as the rotor speed increases. The first term accounts for the reaction of the stator's inductive reactance to a change in current magnitude. It resists current insertion and has no part in mechanical power production. The second term is the back-emf associated with a change in inductance with electrical angle. It is zero in all motors with a rotating stator field when operating at steady state and at all times in rotors with uniform rotational composition, such as surface mounted PM motors. It is referred to as the reluctance component of power production. The third term accounts for the back-emf induced by the changes in the rotor's magnetic flux seen by the stator conductors. This third term is the main component of power production in most PM motors and it is often referred to as $\mathrm{e}_{\mathrm{pm}}$. The fourth term accounts for the back-emf associated with changes in the effective number of turns in the stator.

Because of the speed dependence shown in Eq. (25), the electrical-inductive reactance and induced back-emf tend to be too low at low speeds allowing current shown in Eq. (16) to be excessively high causing burnout. Conversely, at high speeds Eq. (16) shows that the current decreases even to the point where the power input, $\mathrm{P}_{\mathrm{in}}$, is zero or where, at the speed range limit, the power output may not meet requirements.

\section{METHODS OF DIRECT-FLUX CONTROL}

Most approaches to extend the speed range of operation of PM motors focus on weakening the rotor's magnetic flux, $\phi_{\mathrm{r}}$, in order to decrease its contribution to the magnitude of the back-emf and thus allow for power input and generation of stator magnetic field at higher speeds. This weakening may be accomplished in several ways, which are discussed in the following paragraphs.

\section{Vector Control}

The traditional approach to field weakening is vector control in which the effective rotor magnetic flux, $\phi_{\mathrm{r}}$, is suppressed by controlling d-axis stator current to generate a magnetic field that directly opposes and thereby weakens each PM's field. When this approach is used, one must be careful not to demagnetize the PMs. If, in addition, higher torque must be maintained at 
high speed, extra quadrature-axis (q-axis) stator current must be supplied besides the current invested to suppress the rotor's magnetic field which results in higher resistance losses and lower efficiency.

\section{Flux Weakening in Consequent Pole Generator}

As a second approach, research at ORNL [2,3] has produced a consequent pole generator with an external coil connected to the stator. A schematic is shown in Fig. 1. A consequent pole device replaces alternate magnetic poles with ferromagnetic poles and doubles the thickness of the remaining magnets. The alternate pole is induced in the ferromagnetic material as a consequence of the magnet. Current in the external coil controls flux allowing the consequent pole to aid, to do nothing, or to oppose the magnet flux during generation of a back-emf. In Fig. 1(b), flux in the external coil forces the magnet flux into the consequent pole to aid the magnet as it generates the largest back-emf. In Fig. 1(c), the external-flux path accommodates the entire magnet flux thus removing the consequent pole as the magnet generates a back-emf of its traditional equivalent. In Fig. 1(d), the external path provides flux to oppose the magnet thereby reducing the back-emf to a low value. The external coil requires a small amount of additional current but may be used with a conventional pulse width modulation (PWM) inverter and eliminates completely the danger of demagnetizing the magnets. The only increase in complexity is a controller for the auxiliary stator coil current.

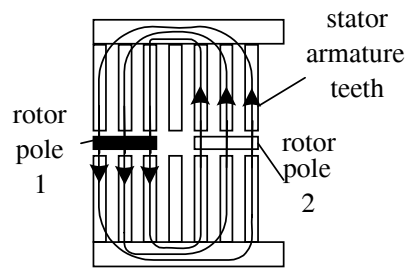

(a) Normal PM flux path

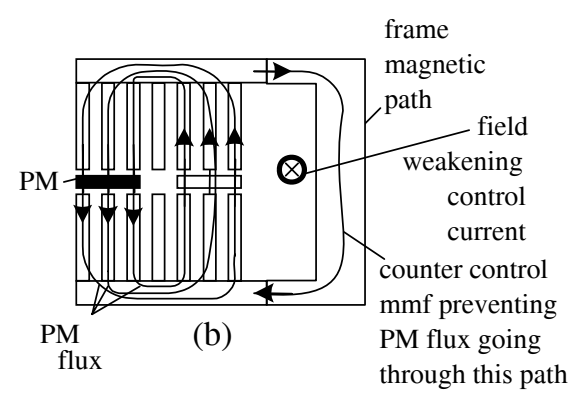

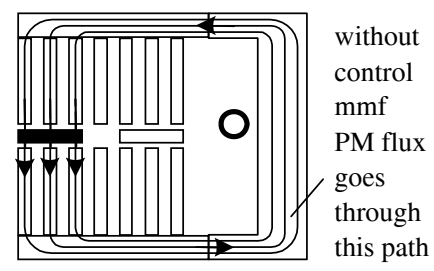

(c)

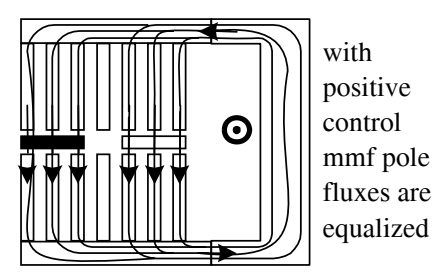

(d)

Fig. 1. Axial-gap consequent pole generator weakened and strengthened by external coil.

\section{High-Strength Undiffused Brushless PM Motor}

An innovative third approach at ORNL [4] employs an external-flux control coil that boosts the magnetic flux at low speeds and weakens the magnetic flux at high speeds. For a conventional PM motor, the air-gap flux density cannot be enhanced effectively, but it can be weakened; consequently, this approach addresses the problem of reduced back-emf at low speeds as well as the problem of excessive back-emf at high speeds. A schematic is shown in Fig. 2. 


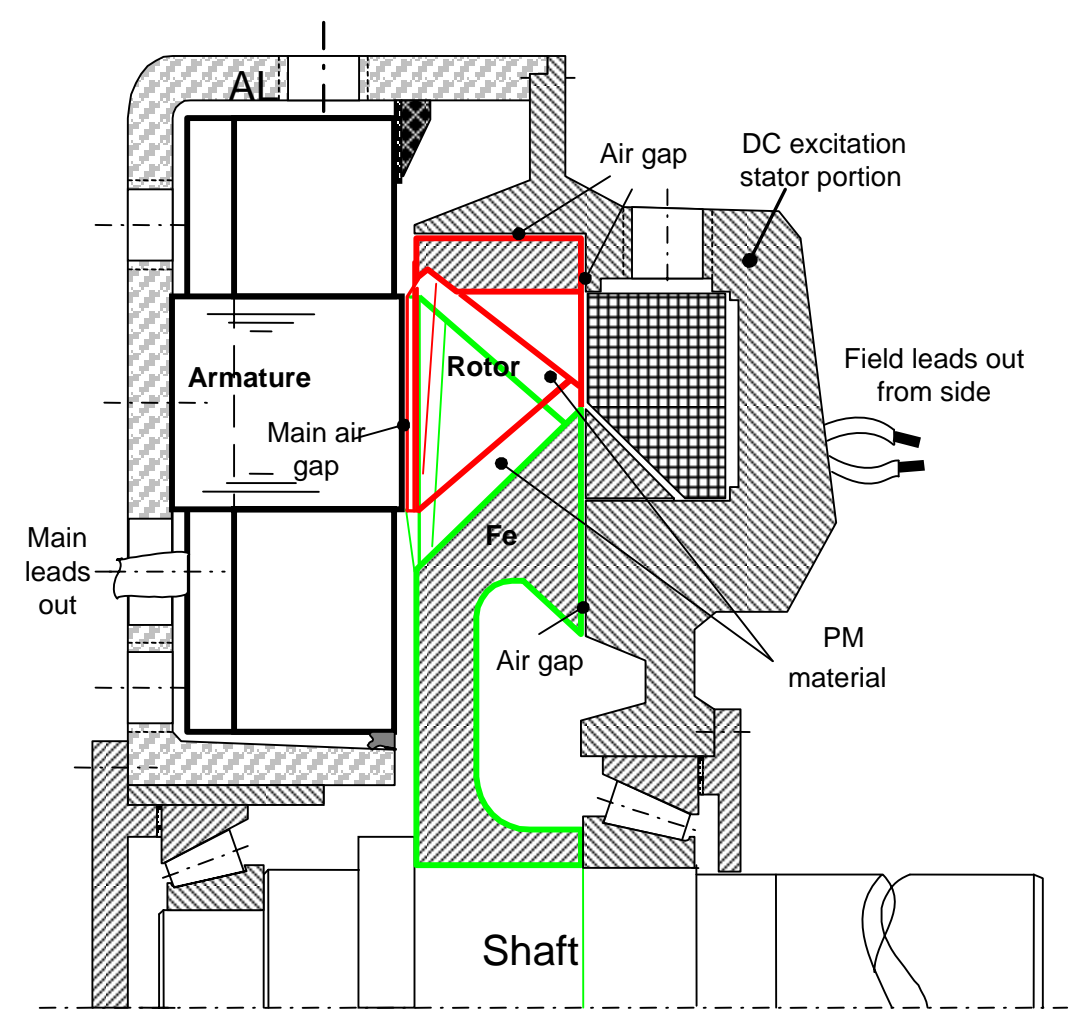

Fig. 2. High-strength (magnetic) undiffused brushless axial-gap PM motor.

The new machine is brushless because it transfers the MMF from the stationary excitation coil to the rotor through two secondary air gaps, identified as "air gap" in Fig. 1. In the new machine, the PM in the rotor prevents magnetic-flux diffusion between the poles and guides the reluctance-flux path. The pole-flux density in the air gap can be higher than what the PM alone can produce thus resulting in a machine with high magnetic strength. The higher magnetic strength manifested itself in higher torque measurements.

The axial flux produced by the direct current (dc) excitation stator coil passes across the secondary air gap into the center part of the rotor (green), into the pole face (green), across the main air gap into a stator tooth, through the stator yoke to the adjacent tooth, back through the main gap into the rotor pole face (red), radially outward through the secondary air gap, and back through the external coil housing to close the flux path.

\section{Magnetic Polarization Variation - Memory Motors}

A fourth approach is to change the magnetization of the PMs by means of MMF pulses [5,6] so that the strength of the rotor poles is changed at will while the motor is operating. This type of motor is a variable-flux motor. If the magnets are demagnetized completely, the result is to decrease the number of poles. This second type of motor is a pole-changing motor. Ostovic calls this motor a Memory Motor because of its ability to memorize the flux-density level in the rotor magnets. 
Figure 3 is a schematic of the Memory Motor. The magnets are polarized circumferentially and placed in a consequent pole configuration. The magnetization of the PMs can be varied by a short-current pulse and does not require a steady demagnetization current characteristic of vector control; consequently, its efficiency is higher. The demagnetizing current flows through the stator windings requiring no special current source. The Memory Motor combines advantages of a wound rotor with its variable flux and a PM motor with no excitation losses that suggests it may be a candidate for an HEV traction drive.

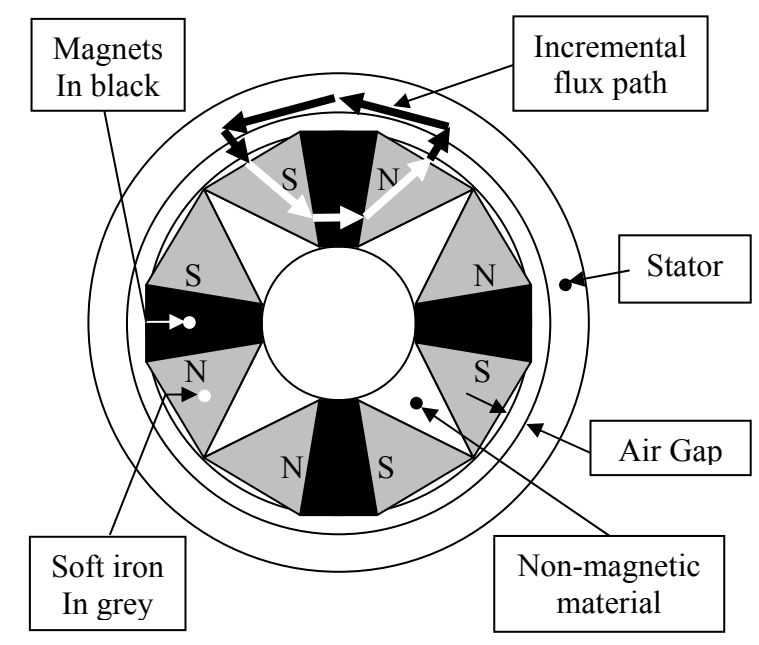

Fig. 3. Variable flux PM motor - Memory Motor.

\section{Magnetic Strength Variation - Thermal Field Weakening}

A fifth approach could be to control the strength of the PMs by actively or passively regulating their temperature below the material's maximum service temperature so that permanent demagnetization will not occur [7].

The effect of thermal field weakening has been observed during PM motor testing as shown in Fig. 4. The stator temperature rose from 100 to $137^{\circ} \mathrm{C}$ during the 15 minute test with the motor's output power held at $30 \mathrm{~kW}$. The increasing stator temperature raised the rotor magnet temperature across the gap thereby reducing the magnetic remanence; consequently, less d-axis current was needed to weaken the magnets so the motor could run at this high speed. The total current is the square root of the d-axis current squared plus q-axis current squared. The reduction in total current observed during the test is a result of the lower d-axis current. The anticipated result is higher efficiency. 


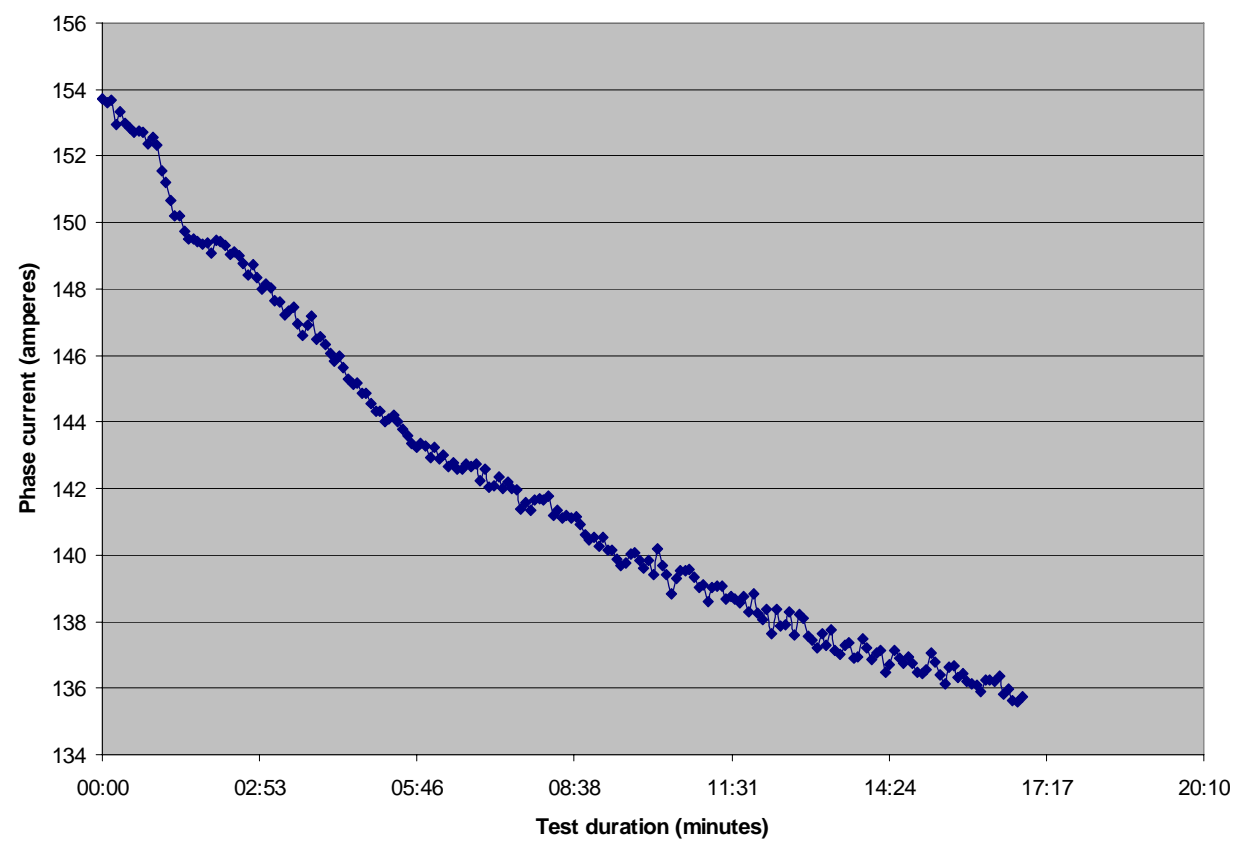

Fig. 4. Field weakening reflected by lower d-axis current component of total phase current as magnet temperature rises.

\section{Changing Number of Stator Turns per Coil}

Relationships between stator current and stator-magnetic flux, as well as between rotor flux and back-emf, are usually considered fixed by construction, but this an unnecessary constraint. Since reducing the back-emf factor eliminates the current wasted to weaken the rotor magnet's field as shown in Fig. 4, a sixth approach could be to decrease the back-emf by reducing the number of turns per coil involved in the energy conversion.

Changing the number of turns per coil can be done by (1) physically changing the number of active turns, (2) changing the turn-to-flux link factor, or (3) changing the number of poles. We have already seen how the Memory Motor can change the number of poles by demagnetizing the magnets. Changing the number of turns may be accomplished by using winding taps with two rectifiers and two switches [8].

For illustration, the speed dependence of the maximum power output for a typical interior PM (IPM) motor with a hypothetical capability to change the number of turns at will is shown in the figures below. Figure 5(a) shows how the base speed, peak power, power, current, and speed ranges grow as the number of turns is reduced 9 to 5. Figure 5(b) shows the limit power curves for a turn-switching scheme focused on maximum power generation. 


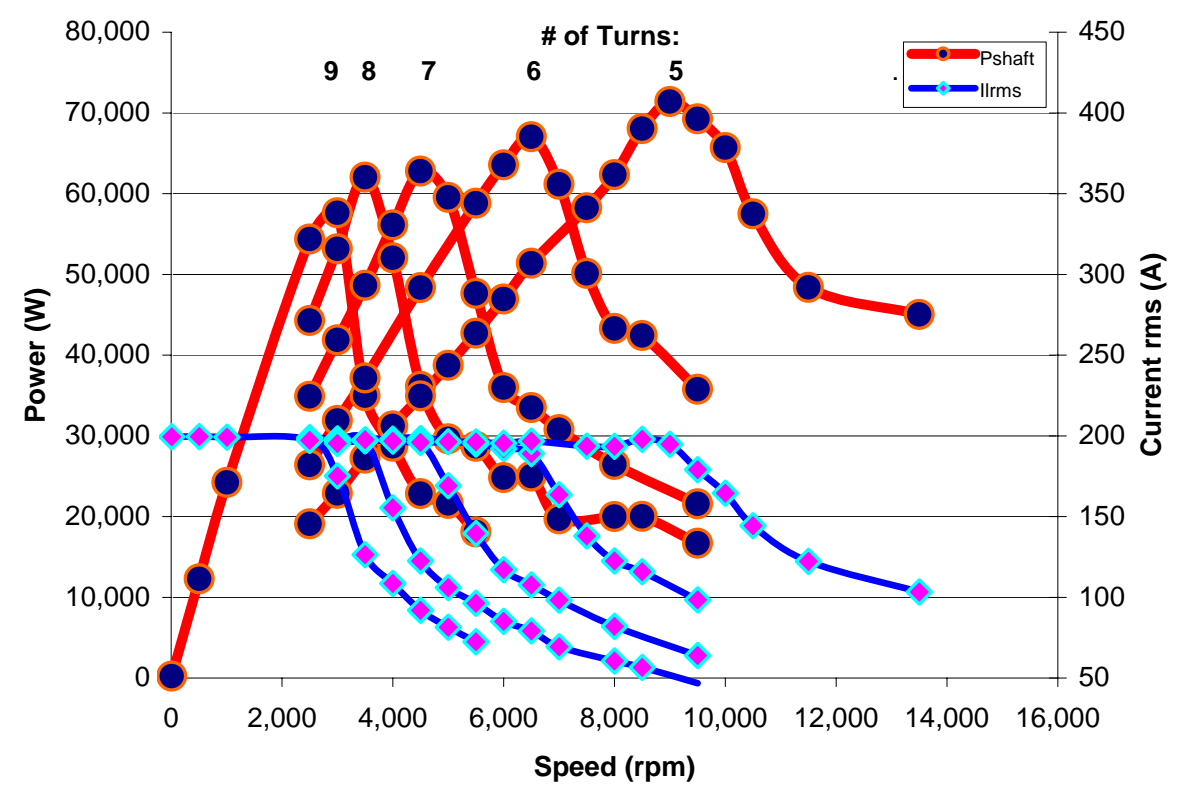

(a) Performance curve dependency on number of turns.

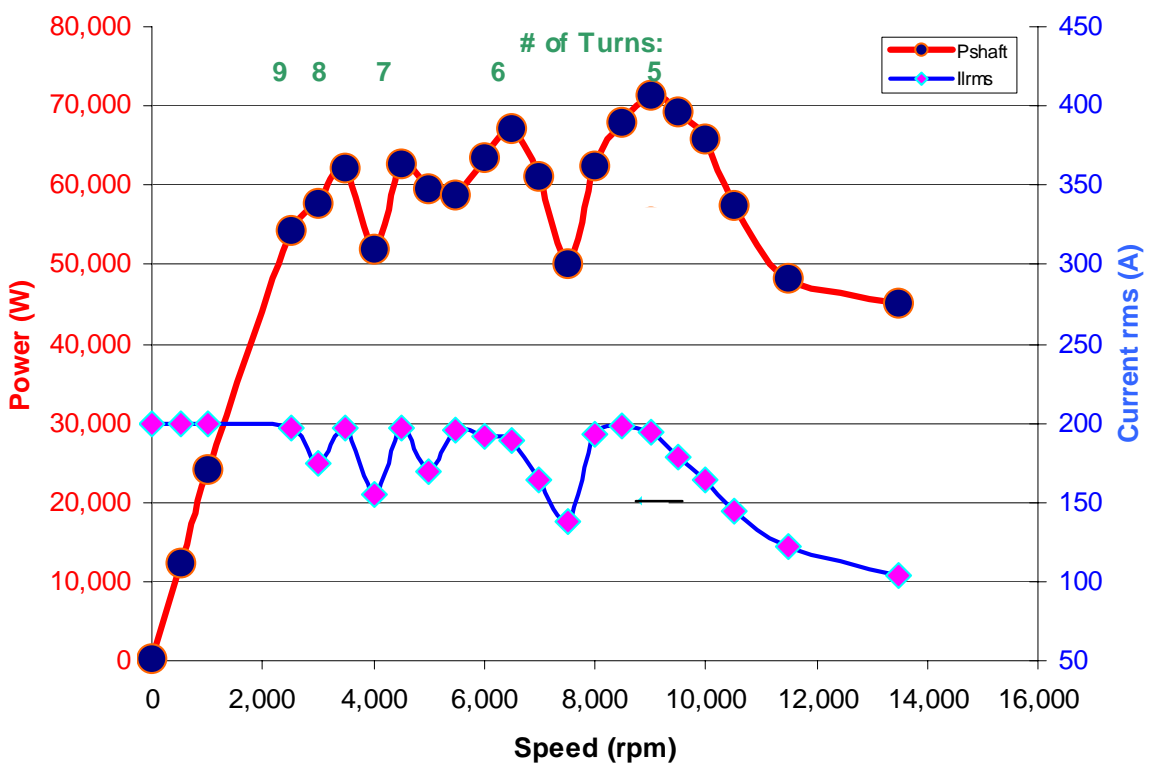

(b) Extending CPSR by reducing the number of turns.

Fig. 5. Using the number of turns per slot to control constant power speed ratio (CPSR). 
A reduction in the effective number of turns per coil, $N_{s}$, decreases the electrical inductance, $\mathcal{L}_{\mathrm{s}}=$ $N_{s}^{2} \mathcal{L}_{1}$, and ohmic resistance, $\mathrm{R}=\mathrm{N}_{\mathrm{s}} \mathrm{R}_{1}$, where $\mathcal{L}_{1}$ and $\mathrm{R}_{1}$ are the inductance and resistance, respectively, of a coil comprising one single turn. As shown by Eq. (16), this approach will result in higher currents for the same voltage levels and in enhanced efficiencies. The following discussion explains how the equation may be derived for the number of turns per coil that will deliver maximum power as a function of angular frequency.

As shown in Fig. 5(a), the number of turns per coil that produces maximum power changes inversely with speed. Analytical determination of the number of turns that delivers maximum power as a function of frequency begins with

$$
P=P\left(\alpha, N_{s}, \omega, L_{d}, L_{q}, \phi, R, V\right),
$$

where
$\alpha$ is the advance angle (the angle between the voltage and the current),
$N_{s}$ is the number of turns per coil,
$\omega$ is the rotational frequency, radians/s,
$L_{d}$ is the d-axis inductance, $\mathrm{H}$,
$L_{d l}$ is the d-axis inductance of a single turn, $\mathrm{H}$,
$L_{q}$ is the q-axis inductance, $\mathrm{H}$,
$L_{q 1}$ is the q-axis inductance of a single turn, $\mathrm{H}$
$\varphi$ is the flux, $\mathrm{V}$-s,
$R$ is the resistance, ohms, and
$V$ is the supply voltage.

The equation, $\partial P / \partial \alpha=0$, is solved for the advance angle that delivers maximum power. The result is

$$
\alpha=\arctan \left(\frac{R-L_{q} \omega}{L_{d} \omega}\right) .
$$

The advance angle is a function of $N_{s}$ because $R=N_{s} R_{1}, L_{q}=N_{s}{ }^{2} L_{q 1}$, and $L_{d}=N_{s}{ }^{2} L_{d l}$; consequently, $\alpha$ as a function of $\mathrm{N}_{\mathrm{s}}$ is substituted into Eq. (26) and the equation,

$$
\partial P\left(\alpha\left\{N_{s}\right\}, N_{s}, \omega, L_{d}, L_{q}, \phi, R, V\right) / \partial N_{s}=0,
$$

is solved for $\mathrm{N}_{\mathrm{s}}$. As part of its modeling effort, ORNL is working to obtain the solution for the number of turns that will achieve maximum power. The problem becomes much more difficult when $\mathrm{R} \neq 0$ and $\alpha=\alpha\left(\mathrm{N}_{\mathrm{s}}\right)$.

\section{Air-Gap Variation}

A seventh approach to weaken the magnetic field is to mechanically increase the air gap. This technique increases the reluctance, which weakens the field by reducing the magnet's flux. The 
concept demands precise control and requires energy to move the rotor while it is spinning. Axial-gap motors with one stator are better suited for this type of control than radial-gap motors because it is easier to control the distance between two flat parallel planes than to control the distance between two low-angle cones. For example, a 0.005 in gap increase of an axial-gap motor requires the rotor to be moved along the axis of rotation by 0.005 in., while a radial-gap motor with a $1^{\circ}$ cone requires the rotor to be moved along the axis of rotation by $0.286 \mathrm{in}$. For example, a $2^{\circ}$ cone requires a 0.143 -in. axial movement to achieve a gap increase of 0.005 in. $\mathrm{Oh}$ and Emadi have applied this method at the Illinois Institute of Technology to improve the efficiency and operating range of wheel motors [9].

\section{APPROACH FOR DETERMINING FLUX-WEAKENING REQUIREMENTS}

The first step in analyzing the impact of flux control techniques on the performance characteristics of a motor is by studying the electromagnetic circuit. Electromagnetic circuits reduce the physics involved in the generation, flow, and conversion of magnetic energy by defining average quantities normally referred to as lumped parameters. When the physics of the PMs and stator electromagnets are represented by their MMFs and their internal reluctances, the magnitude and distribution of the magnetic flux that will circulate on each available path can be calculated using network circuit theory.

A typical magnetic circuit for a PM motor with the magnets of alternating polarity in the rotor is shown in Fig. 6. As shown, the PMs are represented by their MMF and their internal reluctances. The total circuit reluctance and MMF are

$$
\begin{aligned}
\boldsymbol{R}_{\mathrm{t}} & =\boldsymbol{R}_{\mathrm{r} 1}+\boldsymbol{R}_{\mathrm{m} 1}+\boldsymbol{R}_{\mathrm{g} 1}+\boldsymbol{R}_{\mathrm{s} 1}+\boldsymbol{R}_{\mathrm{sbi}}+\boldsymbol{R}_{\mathrm{s} 2}+\boldsymbol{R}_{\mathrm{g} 2}+\boldsymbol{R}_{\mathrm{m} 2}+\boldsymbol{R}_{\mathrm{r} 2} \\
\mathcal{F}_{\mathrm{t}} & =\mathcal{F}_{\mathrm{m} 1}+\mathcal{F}_{\mathrm{m} 2}+\mathcal{F}_{\mathrm{s} 1}+\mathcal{F}_{\mathrm{s} 2}=\phi_{\mathrm{mr}} \boldsymbol{R}_{\mathrm{m} 1}+\phi_{\mathrm{mr}} \boldsymbol{R}_{\mathrm{m} 2}+\mathrm{I} \mathrm{N}_{\mathrm{s}}
\end{aligned}
$$

Depending on its direction, the stator current's MMF increases or decreases the magnetic flux in the loop. Once the MMFs and reluctances are known, the flux can be calculated from Eq. (6) where $R$ represents reluctance, $F$ represents MMF of the magnet, $\phi$ represents magnetic flux, subindices 1 and 2 refer to each half the loop, $g$ stands for the air gap, s stands for the stator, $r$ stands for the rotor, mr stands for magnet remanence, and sbi stands for the stator's back iron.

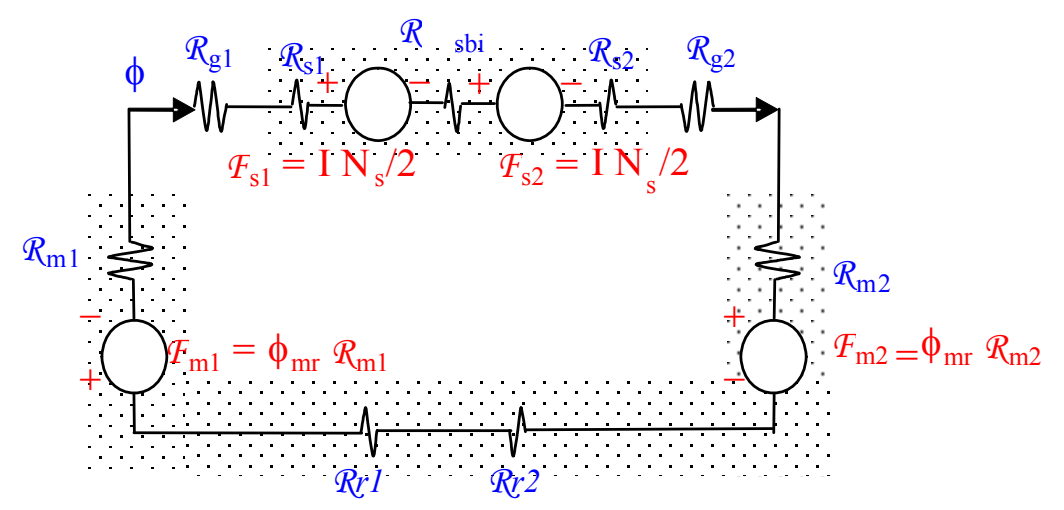

Fig. 6. Magnetic circuit of PM motor. 
The total flux is $\phi=\mathscr{F}_{t} / \boldsymbol{R}_{\mathrm{t}}$.

The rotor flux contribution is $\phi_{\mathrm{r}}=\phi(\mathrm{I}=0)=\left(\mathscr{F}_{\mathrm{t}}-\mathrm{I} \mathrm{N} \mathrm{N}_{\mathrm{s}}\right) / \mathscr{R}_{\mathrm{t}}=\left(\phi_{\mathrm{mr}} \mathbb{R}_{\mathrm{m} 1}+\phi_{\mathrm{mr}} \mathcal{R}_{\mathrm{m} 2}\right) / \mathcal{R}_{\mathrm{t}}$.

The stator flux contribution is $\phi_{\mathrm{s}}=\phi\left(\mathrm{B}_{\mathrm{r}}=0\right)=\left(\mathscr{F}_{\mathrm{t}}-\left(\phi_{\mathrm{mr}} \mathcal{R}_{\mathrm{m} 1}+\phi_{\mathrm{mr}} \mathcal{R}_{\mathrm{m} 2}\right)\right) / \boldsymbol{R}_{\mathrm{t}}=\mathrm{I} \mathrm{N}_{\mathrm{s}} / \mathscr{R}_{\mathrm{t}}$.

Consequent pole machines have all magnets placed in the rotor with the same orientation. As a result, virtual poles develop in the spaces on the rotor between the magnets. Figure 7 shows the magnetic circuit of a consequent pole machine created by taking every other magnet in a standard PM rotor, moving it from the air-gap region to stack with its $\mathrm{N}$ pole agains its neighbors $\mathrm{S}$ pole, and rreplacing it magnet. As a result, we have a rotor with PMs of double the original thickness, all oriented in the same direction, and with iron in between them.

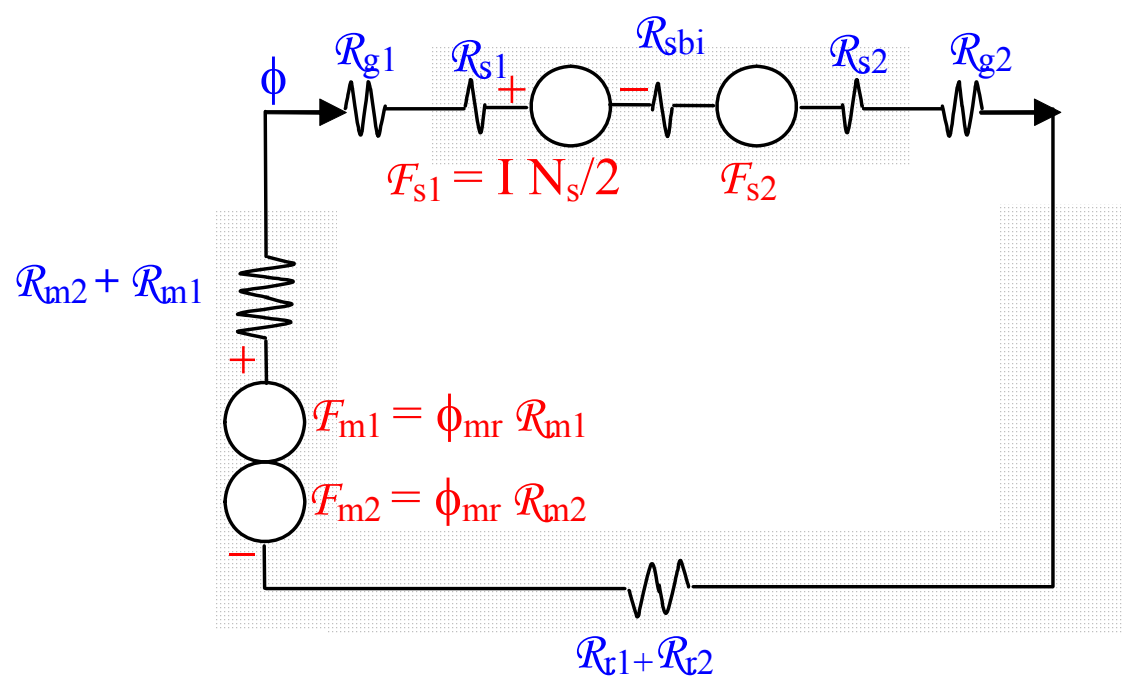

Fig. 7. Magnetic circuit of a consequent pole PM motor with the same MMFs and reluctances of the motor in Fig. 6.

For this consequent pole configuration, the resulting fluxes are the same. The difference is that now the virtual pole in air-gap number 2 is a soft iron pole and its flux flow can be changed more readily than with the PM material. For instance, in Fig. 8 a circuit is shown with an additional branch representing an externally controlled MMF source, $F_{\mathrm{x}}=\mathrm{I}_{\mathrm{x}} \mathrm{N}_{\mathrm{x}}$, that can either decrease or increase the flux, $\phi_{\mathrm{g} 2}$, across air-gap number 2 . The flux through air-gaps, gx1 and gx2, produces no torque.

In the figure, there are shown three possible connection points for the bypassed flux return path labeled P1, P2, and P3. It is most important to know which of the three or what fraction of the bypassed flux each of the three carries since the effect on the back-emf depends on it. The solution of the circuit yields the flux at each of the air-gaps and at each of the rotor coils. The torque generated is proportional to the air-gap flux while the back-emf depends on the coils flux. 


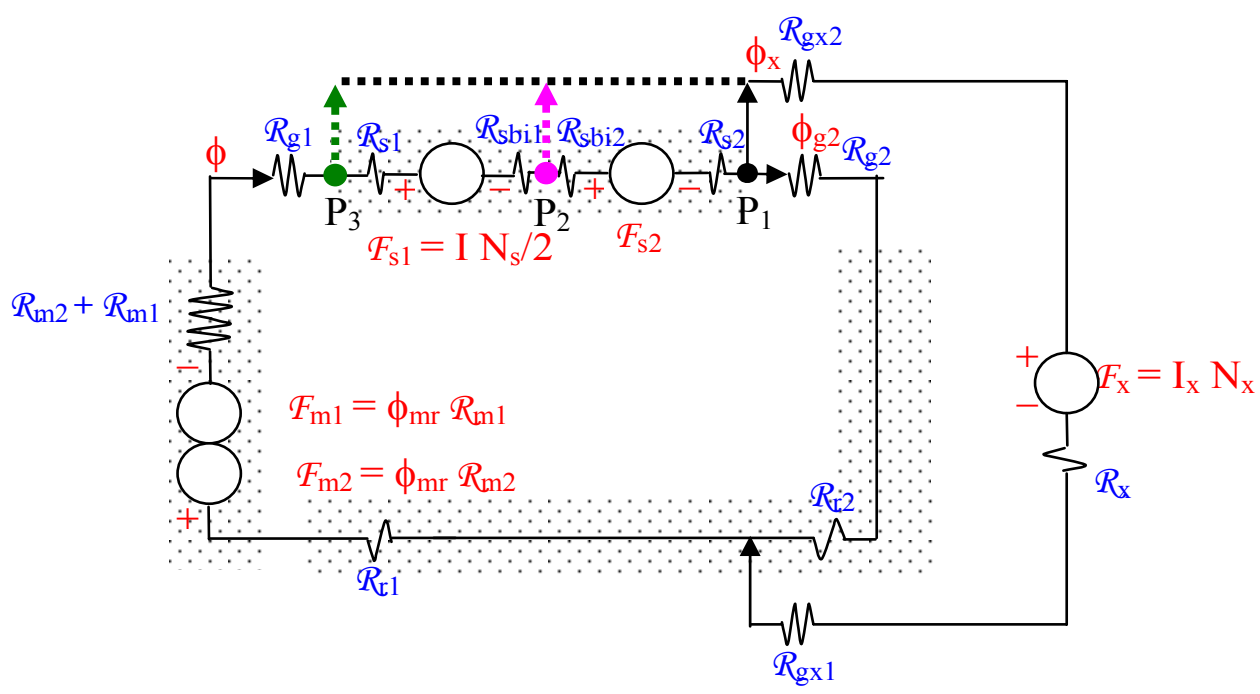

Fig. 8. Magnetic circuit of the consequent pole PM motor in Fig. 7 with the addition of an externally controlled MMF.

For the case in which the connection is fully at P1, the solution of the circuit produces the following fluxes

$$
\begin{aligned}
\phi & =\left(\mathcal{F}_{\mathrm{a}}\left(\mathscr{R}_{\mathrm{b}}+\mathscr{R}_{\mathrm{c}}\right)-\mathcal{F}_{\mathrm{x}} \mathscr{R}_{\mathrm{c}}\right) / \mathrm{C}_{1} \\
\phi_{\mathrm{g} 2} & =\left(\mathcal{F}_{\mathrm{a}} \mathscr{R}_{\mathrm{b}}-\mathcal{F}_{\mathrm{x}} \mathscr{R}_{\mathrm{a}}\right) / \mathrm{C}_{1} \\
\phi_{\mathrm{x}} & =\left(\mathcal{F}_{\mathrm{a}} \mathscr{R}_{\mathrm{c}}-\mathcal{F}_{\mathrm{x}}\left(\mathscr{R}_{\mathrm{a}}+\mathscr{R}_{\mathrm{c}}\right)\right) / \mathrm{C}_{1}
\end{aligned}
$$

where

$$
\begin{aligned}
& \mathcal{F}_{\mathrm{a}}=\mathscr{F}_{\mathrm{m} 1}+\mathcal{F}_{\mathrm{m} 2}+\mathrm{I} \mathrm{N}_{\mathrm{s}} \\
& \mathcal{F}_{\mathrm{x}}=\mathrm{I}_{\mathrm{x}} \mathrm{N}_{\mathrm{x}} \\
& \mathrm{C}_{1}=\mathbb{R}_{\mathrm{a}} \mathbb{R}_{\mathrm{b}}+\mathbb{R}_{\mathrm{a}} R_{\mathrm{c}}+\mathscr{R}_{\mathrm{b}} R_{\mathrm{c}} \\
& \mathscr{R}_{\mathrm{a}}=\boldsymbol{R}_{\mathrm{r} 1}+\boldsymbol{R}_{\mathrm{m} 1}+\boldsymbol{R}_{\mathrm{m} 2}+\boldsymbol{R}_{\mathrm{g} 1}+\boldsymbol{R}_{\mathrm{s} 1}+\boldsymbol{R}_{\mathrm{sbi} 1}+\boldsymbol{R}_{\mathrm{sbi} 2}+\boldsymbol{R}_{\mathrm{s} 2} . \\
& \mathscr{R}_{\mathrm{b}}=\mathscr{R}_{\mathrm{gx} 1}+\boldsymbol{R}_{\mathrm{gx} 2}+\boldsymbol{R}_{\mathrm{x}} \\
& \mathscr{R}_{\mathrm{c}}=\boldsymbol{R}_{\mathrm{g} 2}+\boldsymbol{R}_{\mathrm{r} 2}
\end{aligned}
$$

Phasor diagrams look at motors from the electrical point of view using a rotating coordinate system. They are most useful since electrical parameters are more readily measurable than magnetic parameters. Their reference axes are named d-axis and q-axis. They correspond to those rotor positions that yield the maximum and minimum amounts of magnetic flux linked in the stator coils. In PM motors, the d-axis corresponds to the center of a rotor's PM, while the qaxis corresponds to the midpoint in the space separating a PM from its closest PM of different polarity. The fundamental $\mathrm{d}$ - and q-axis variables result from a power-invariant transformation of its multiphase stationary equivalents. This allows for separate equivalent electromagnetic circuits for each of the two axes. Figures 9 and 10 show electromagnetic and phasor diagrams representative of all PM motors driven by sinusoidal voltages. 


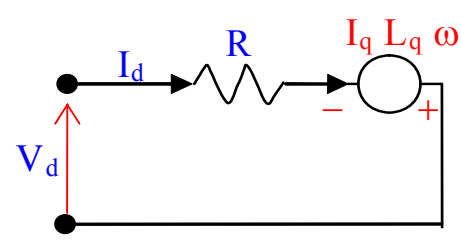

(a) d-axis

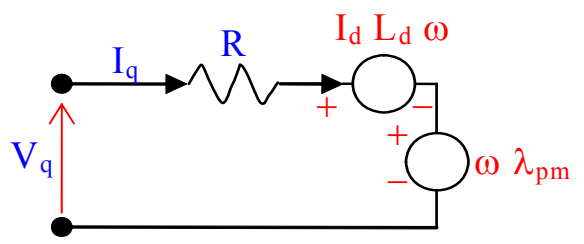

(b) q-axis

Fig. 9. Equivalent circuit schematics of the $d$ and $q$ electromagnetic circuits in a PM motor.

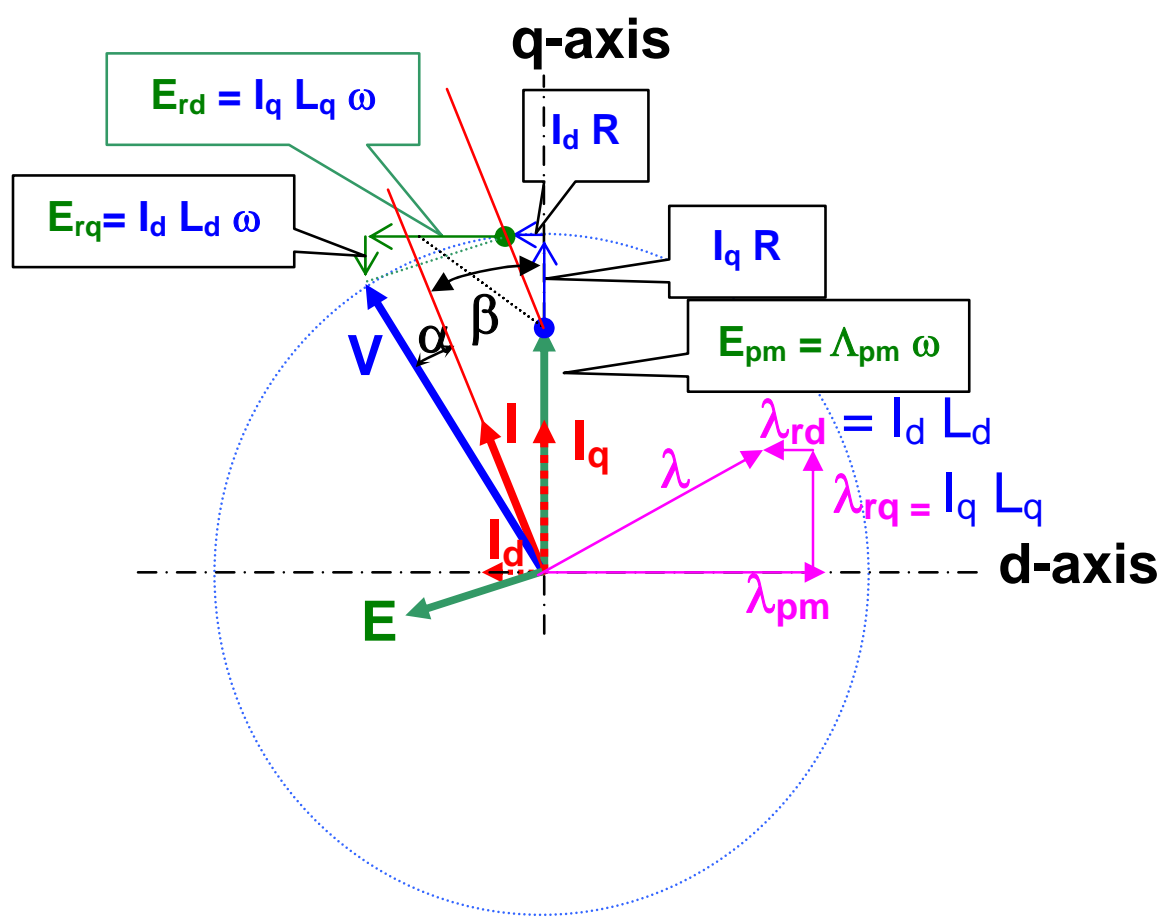

Fig. 10. Standard electric and magnetic phasor diagrams of a PM motor with $I_{d}$ negative.

In essence, they are the graphical representations of Eq. (15) in terms of time averaged quantities in rotating field coordinates.

The power input per pole pair is then

$$
P_{\text {in }}=I V \cos (\alpha)=I_{q}\left(E_{p m}+I_{q} R+I_{d} L_{d} \omega\right)+I_{d}\left(I_{d} R-I_{q} L_{q} \omega\right)
$$

The power output is

$$
\begin{aligned}
& P_{\text {out }}=P_{\text {in }}-P_{\text {loss }}=I_{q} V_{q}+I_{d} V_{d} \\
& P_{\text {out }}=I_{q}\left(E_{p m}+L_{d} I_{d} \omega\right)+I_{d}\left(-L_{q} I_{q} \omega\right)=I_{q}\left(E_{p m}+I_{d}\left(L_{d}-L_{q}\right) \omega\right)
\end{aligned}
$$


Defining the saliency ratio as

$$
\xi=\mathrm{L}_{\mathrm{q}} / \mathrm{L}_{\mathrm{d}}
$$

then

$$
P_{\text {out }}=I_{q}\left(E_{p m}+I_{d} L_{d}(1-\xi) \omega\right) .
$$

In terms of the phase current, $I_{d}=-I \sin (\beta)$ and $I_{q}=I \cos (\beta)$

$$
P_{\text {out }}=I \cos (\beta) E_{p m}+0.5 I^{2} \sin (2 \beta) L_{d}(\xi-1) \omega .
$$

In IPMs, $\mathrm{L}_{\mathrm{q}}>\mathrm{L}_{\mathrm{d}}$; thus if $\mathrm{I}_{\mathrm{d}}$ is negative, as shown in Fig. 10, in addition to flux weakening, the new term introduced by the presence of $\mathrm{I}_{\mathrm{d}}$ has a positive power contribution.

The most common operational constraints for a motor are voltage and current limits. The supply voltage limit, $\mathrm{V}_{\max }$, depends on the dc-link voltage and the inverter. The current limit, $\mathrm{I}_{\max }$, depends on the stator losses, cooling capabilities, and on the current limit of the inverter

$$
\begin{aligned}
& I=\left(I_{d}^{2}+I_{q}^{2}\right)^{1 / 2} \leq I_{\max }, \\
& V=\left(V_{d}^{2}+V_{q}{ }^{2}\right)^{1 / 2}=\left(\left(E_{p m}+I_{q} R+I_{d} L_{d} \omega\right)^{2}+\left(I_{d} R+I_{q} L_{q} \omega\right)^{2}\right)^{1 / 2} \leq V_{\max } .
\end{aligned}
$$

For operation at the voltage limit, considering that $\mathrm{E}_{\mathrm{pm}}=\omega \lambda_{\mathrm{pm}}$ and neglecting the stator resistance, we obtain the relationship between $I_{d}$ and $I_{q}$ as a function of speed

$$
\left(\lambda_{\mathrm{pm}}+\mathrm{I}_{\mathrm{d}} \mathrm{L}_{\mathrm{d}}\right)^{2}+\left(\mathrm{I}_{\mathrm{q}} \mathrm{L}_{\mathrm{q}}\right)^{2}=\left(\mathrm{V}_{\max } / \omega\right)^{2} .
$$

From Eq. (35), the amount of d-axis current as a function of quadrature current is

$$
\mathrm{I}_{\mathrm{d}}=-\lambda_{\mathrm{pm}} / \mathrm{L}_{\mathrm{d}}+1 / \mathrm{L}_{\mathrm{d}}\left[\left(\mathrm{V}_{\max } / \omega\right)^{2}-\left(\mathrm{I}_{\mathrm{q}} \mathrm{L}_{\mathrm{q}}\right)^{2}\right]^{1 / 2}
$$

and the phase current angle and magnitude are

$$
\beta=\arctan \left[\mathrm{I}_{\mathrm{d}} / \mathrm{I}_{\mathrm{q}}\right]=\arctan \left[\lambda_{\mathrm{pm}} /\left(\mathrm{I}_{\mathrm{q}} \mathrm{L}_{\mathrm{d}}\right)+1 / \mathrm{L}_{\mathrm{d}}\left[\left(\mathrm{V}_{\max } /\left(\mathrm{I}_{\mathrm{q}} \omega\right)\right)^{2}-\mathrm{L}_{\mathrm{q}}{ }^{2}\right]^{1 / 2}\right]
$$

and

$$
\mathrm{I}=\mathrm{I}_{\mathrm{q}} / \cos (\beta) .
$$

When $\lambda_{\text {rd }}=L_{q}, I_{d}$ opposes $\lambda_{\text {pm }}$ directly; when $I_{d}$ is negative the degree of flux weakening achieved, or weakening factor, could be defined as the ratio

$$
\xi_{\mathrm{w}}=-\mathrm{L}_{\mathrm{d}} \mathrm{I}_{\mathrm{d}} / \lambda_{\mathrm{pm}}=-\mathrm{I}_{\mathrm{d}} / \mathrm{I}_{\mathrm{ch}},
$$


where $\mathrm{I}_{\mathrm{ch}}=\mathrm{L}_{\mathrm{d}} / \lambda_{\mathrm{pm}}$ is the so-called characteristic current of the motor. For instance, for a case in which $\mathrm{L}_{\mathrm{q}}=2.5 \mathrm{mH}$ and $\lambda_{\mathrm{pm}}=0.15 \mathrm{~V} \mathrm{~s}, \mathrm{I}_{\mathrm{ch}}=60 \mathrm{~A}$ and thus the weakening factor is

$$
\xi_{\mathrm{w}}=-\mathrm{I}_{\mathrm{d}} / 60
$$

Then a current with a direct component $\mathrm{I}_{d}=-30$ A will weaken the magnet $50 \%$ and an $I_{d}=-60$ A will demagnetize it.

Since locomotion applications tend to prefer motors with wide speed ranges to eliminate the need for or reduce the complexity of gear boxes, it is important to find ways to increase the speed range of PM motors. One obvious possibility is to use a multilevel voltage source where available voltage would increase with rotor speed. Drive costs being already the major component of a PM drive system may limit this approach to two stages with the higher stage enabled at the higher speeds. Presently, improvements in stator and rotor topologies together with control approaches have better overall performance and opportunity to lower cost.

\section{DISCUSSION}

Control of the flux crossing the air gap is the ultimate goal of all RTFC approaches. There are three ways to accomplish RTFC: (1) changing the magnetic energy flow paths, (2) selectively changing the magnetic material properties, and (3) changing the degree of coupling between the stator and the rotor. To date, most of the efforts have focused on the first approach. We feel that the alternatives should be examined for applicability to FreedomCAR HEVs.

Vector control at the stator terminal is the conventional approach for RTFC. By making some of the stator flux oppose the rotor magnet flux, flux weakening occurs which is a clear choice for extending the speed range of operation. An excellent discussion of vector-control and flux weakening can be found in Ref. [10]. Some rotor designs, such as IPMs and consequent pole motors, facilitate flow path manipulation.

Redirecting the rotor's magnetic flux to reduce the back-emf also reduces the torque produced since the diverted flux flows through non-torque producing paths. Power losses resulting from diverted fluxes should be carefully studied to ensure that they are not excessive for the back-emf reduction. John Hsu's concept of a bidirectional path capable of injecting to as well as draining magnetic flux from the torque producing areas is quite promising.

Changes in the magnetic strength of the PM material can be achieved by controlling its temperature or by using magnetizing and demagnetizing current pulses as needed, as in polechanging PM machines.

Changes in the degree of coupling between the stator and the rotor involve control of the number of active turns in the stator and/or their effectiveness in linking rotor originated flux. This could be done by electronically disconnecting some of the stator turns by means of built-in solid-state gates or by draining some of the tooth-flux laterally. 
Table 1 summarizes and compares different methods of RTFC as they are applied to a synchronous PM motor with torque and speed control. The column entitled "Relative complexity" indicates the simplifications that may be achieved in control of the basic motor. Significant research has been completed on the first three and the last method. Others are mostly conceptual. 
Table 1. Comparison of RTFC for synchronous PM motor with torque and speed control

\begin{tabular}{|c|c|c|c|c|c|c|c|}
\hline Method & $\begin{array}{c}\text { Real time } \\
\text { variable }\end{array}$ & Ref. & $\begin{array}{c}\text { Technique for } \\
\text { varying flux }\end{array}$ & Maturity & Advantages and limitations & $\begin{array}{c}\text { Deployment } \\
\text { difficulty }\end{array}$ & $\begin{array}{c}\text { Relative } \\
\text { complexity }\end{array}$ \\
\hline $\begin{array}{l}\text { Conventional } \\
\text { Vector } \\
\text { Control }\end{array}$ & $\begin{array}{l}\text { Decomposed } \\
\text { stator currents, } \\
\mathrm{i}_{\mathrm{d}} \text { for } \\
\text { weakening and } \\
\mathrm{i}_{\mathrm{q}} \text { for torque } \\
\text { production. }\end{array}$ & 1 & $\begin{array}{l}\text { Decomposes stator } \\
\text { current into a } \\
\text { component that } \\
\text { opposes rotor } \\
\text { magnet and a } \\
\text { component that } \\
\text { produces torque. }\end{array}$ & $\begin{array}{l}\text { Commercially } \\
\text { mature. }\end{array}$ & $\begin{array}{l}\text { Employs inverter control of stator } \\
\text { current without additional hardware. } \\
\text { Requires more current which lowers } \\
\text { efficiency. }\end{array}$ & $\begin{array}{l}\text { Requires } \\
\text { complex real } \\
\text { time digital } \\
\text { signal processor } \\
\text { (DSP) } \\
\text { calculations. }\end{array}$ & $\begin{array}{l}\text { High-speed } \\
\text { DSP } \\
\text { calculations. } \\
\text { Expensive } \\
\text { absolute } \\
\text { encoder. }\end{array}$ \\
\hline Flux Flipping & $\begin{array}{l}\text { Current in } \\
\text { stationary coil. }\end{array}$ & 2 & $\begin{array}{l}\text { Double magnet } \\
\text { thickness and } \\
\text { replace alternate } \\
\text { magnets with } \\
\text { congruent } \\
\text { ferromagnetic slugs. }\end{array}$ & $\begin{array}{l}\text { Demonstrated } \\
10: 1 \\
\text { weakening } \\
\text { ratio with } \\
\text { small } \\
\text { generator in } \\
\text { laboratory. } \\
\text { Patent issued. }\end{array}$ & $\begin{array}{l}\text { Manual control of a rheostat allows } \\
\text { simple control of the generator } \\
\text { output voltage. Can be used with a } \\
\text { conventional PWM inverter. } \\
\text { Joule heat loss in the stationary coil } \\
\text { is expected to be about } 3 \% \text {, the same } \\
\text { as for a dc machine. } \\
\text { Current losses are steady. }\end{array}$ & $\begin{array}{l}\text { Simple manual } \\
\text { rheostat control } \\
\text { of stationary coil } \\
\text { current in lab } \\
\text { must be replaced } \\
\text { with a current } \\
\text { controller in the } \\
\text { system. }\end{array}$ & $\begin{array}{l}\begin{array}{l}\text { Incremental } \\
\text { encoder. }\end{array} \\
\text { Stationary } \\
\text { control coil. } \\
\text { Requires } \\
\text { simple } \\
\text { algorithm to } \\
\text { control } \\
\text { current in } \\
\text { stationary } \\
\text { coil. }\end{array}$ \\
\hline $\begin{array}{l}\text { High Strength } \\
\text { Undiffused } \\
\text { Brushless }\end{array}$ & $\begin{array}{l}\text { Current in } \\
\text { stationary coil. }\end{array}$ & 4 & $\begin{array}{l}\text { Strengthens or } \\
\text { weakens flux in gap } \\
\text { with flux from } \\
\text { stationary coil. } \\
\text { Iron path carries } \\
\text { flux to gap and is } \\
\text { focused to prevent } \\
\text { leakage with PMs. }\end{array}$ & $\begin{array}{l}\text { Completed } \\
\text { early lab demo } \\
\text { showing } \\
\text { potential. } \\
\text { Patent pending } \\
\text { for advanced } \\
\text { technology in } \\
\text { this area. }\end{array}$ & $\begin{array}{l}\text { May strengthen as well as weaken } \\
\text { magnetic field. Can be used with a } \\
\text { conventional PWM inverter. } \\
\text { Joule heat loss in the stationary coil } \\
\text { is expected to be about } 3 \% \text {, the same } \\
\text { as for a dc machine. } \\
\text { Current losses are steady. }\end{array}$ & $\begin{array}{l}\text { A circuit to } \\
\text { control the } \\
\text { current in the } \\
\text { stationary coil } \\
\text { must be added to } \\
\text { the inverter drive } \\
\text { system. }\end{array}$ & $\begin{array}{l}\text { Incremental } \\
\text { encoder. } \\
\text { Stationary } \\
\text { control coil. } \\
\text { Requires } \\
\text { simple } \\
\text { algorithm to } \\
\text { control } \\
\text { current in } \\
\text { stationary } \\
\text { coil. }\end{array}$ \\
\hline
\end{tabular}


Table 1. Comparison of RTFC for synchronous PM motor with torque and speed control (cont'd)

\begin{tabular}{|c|c|c|c|c|c|c|c|}
\hline Method & $\begin{array}{c}\text { Real time } \\
\text { variable }\end{array}$ & Ref. & $\begin{array}{c}\text { Technique for varying } \\
\text { flux }\end{array}$ & Maturity & Advantages and limitations & $\begin{array}{c}\text { Deployment } \\
\text { difficulty }\end{array}$ & $\begin{array}{c}\text { Relative } \\
\text { complexity }\end{array}$ \\
\hline $\begin{array}{l}\text { Pole } \\
\text { Strength } \\
\text { Change }\end{array}$ & $\begin{array}{l}\text { Magnetic } \\
\text { field } \\
\text { intensity. }\end{array}$ & None & $\begin{array}{l}\text { Change temperature of } \\
\text { magnet for delta flux } \\
\text { control over } \\
\text { recoverable B range. }\end{array}$ & $\begin{array}{l}\text { A natural } \\
\text { weakening has } \\
\text { been observed } \\
\text { during testing of } \\
\text { PM motors as } \\
\text { rotor magnet } \\
\text { temperature rises. }\end{array}$ & $\begin{array}{l}\text { Can achieve small field weakening } \\
\text { because heat is always available. } \\
\text { Weakens back-emf directly so } \\
\text { efficiency is not reduced. Can be used } \\
\text { with a conventional PWM inverter. } \\
\text { A temperature control system will be } \\
\text { needed to cool the magnets when the } \\
\text { motor demand increases. }\end{array}$ & $\begin{array}{l}\text { Temperature } \\
\text { must not exceed } \\
\text { range of B field } \\
\text { recoverability. }\end{array}$ & $\begin{array}{l}\text { Refrigeration } \\
\text { needed to restore } \\
\text { lower } \\
\text { temperature. }\end{array}$ \\
\hline $\begin{array}{l}\text { Pole } \\
\text { Number } \\
\text { Change } \\
\text { (memory } \\
\text { motors) }\end{array}$ & $\begin{array}{l}\text { Kill and } \\
\text { revive } \\
\text { certain } \\
\text { poles to } \\
\text { change } \\
\text { pole } \\
\text { number. }\end{array}$ & 5 & $\begin{array}{l}\text { Uses vector control } \\
\text { d-axis current to } \\
\text { demagnetize and re- } \\
\text { magnetize magnet } \\
\text { poles. }\end{array}$ & $\begin{array}{l}\text { Is in early } \\
\text { research stage. } \\
\text { Patent has been } \\
\text { applied for. }\end{array}$ & $\begin{array}{l}\text { Can be de- and re-magnetized with } \\
\text { short pulses of stator current combining } \\
\text { high efficiency of PM motor with air- } \\
\text { gap flux controllability of a wound } \\
\text { synchronous motor. } \\
\text { Load component of stator current } \\
\text { cannot influence the magnet state. } \\
\text { Challenging deployment. }\end{array}$ & $\begin{array}{l}\text { Requires precise } \\
\text { control of d-axis } \\
\text { current as well as } \\
\text { magnet material } \\
\text { that is repeatedly } \\
\text { remagnetizable. }\end{array}$ & $\begin{array}{l}\text { High-speed DSP } \\
\text { calculations. } \\
\text { Expensive } \\
\text { absolute encoder. }\end{array}$ \\
\hline $\begin{array}{l}\text { Coil } \\
\text { Number } \\
\text { Change }\end{array}$ & $\begin{array}{l}\text { Number of } \\
\text { active turns } \\
\text { per stator } \\
\text { coil. }\end{array}$ & 7 & $\begin{array}{l}\text { Winding taps, two } \\
\text { rectifiers, and two } \\
\text { switches are used to } \\
\text { change the number of } \\
\text { active turns. }\end{array}$ & $\begin{array}{l}\text { Applicable } \\
\text { circuitry has been } \\
\text { suggested in a } \\
\text { paper. Is in early } \\
\text { research stage. }\end{array}$ & $\begin{array}{l}\text { Weakens back-emf directly so } \\
\text { efficiency is not reduced. Can be used } \\
\text { with a conventional PWM inverter. } \\
\text { Requires additional winding taps, } \\
\text { switches, and rectifiers. }\end{array}$ & $\begin{array}{l}\text { Circuit } \\
\text { connections to } \\
\text { stator coils will } \\
\text { be challenging } \\
\text { and provide } \\
\text { potential failure } \\
\text { sites. }\end{array}$ & $\begin{array}{l}\text { Additional taps } \\
\text { to stator coil, } \\
\text { switches, and } \\
\text { rectifiers. }\end{array}$ \\
\hline $\begin{array}{l}\text { Gap } \\
\text { Change }\end{array}$ & Gap width. & 8 & $\begin{array}{l}\text { Increase or decrease } \\
\text { reluctance by opening } \\
\text { or closing gap during } \\
\text { operation. }\end{array}$ & $\begin{array}{l}\text { Limited work on } \\
\text { an axial-gap } \\
\text { motor at ANL } \\
\text { was successful. } \\
\text { Application to } \\
\text { radial-gap will be } \\
\text { difficult. }\end{array}$ & $\begin{array}{l}\text { Weakens back-emf directly so } \\
\text { efficiency is not reduced. Can be used } \\
\text { with a conventional PWM inverter. } \\
\text { Difficult to maintain dimensional } \\
\text { control. Quantity of energy needed to } \\
\text { initiate the gap change was close to the } \\
\text { energy saved. }\end{array}$ & $\begin{array}{l}\text { Requires a servo } \\
\text { controlled } \\
\text { mechanical } \\
\text { system to } \\
\text { regulate the gap. }\end{array}$ & $\begin{array}{l}\text { Adds an } \\
\text { additional servo } \\
\text { system to the } \\
\text { baseline system. }\end{array}$ \\
\hline
\end{tabular}




\section{CONCLUSIONS}

1. A number of methods of RTFC to increase the speed range while maintaining the efficiency of a synchronous PM motor have been presented in the open literature. Seven are discussed in this report.

2. Conventional vector control maintains a torque producing quadrature current, $\mathrm{i}_{\mathrm{q}}$, and a magnet field-weakening $d$-axis current, $i_{d}$. The component of the $\mathrm{dc} d$-axis current must be maintained during operation at high speed and results in increased stator current resistance losses with the accompanying loss in efficiency. Vector control is well established and allows speed range extension by flux weakening. It does require an expensive absolute encoder and fast control algorithms.

3. In general, efficiency considerations make those methods of flux control that require temporary intervention or pulses preferable to those requiring continuous action during operation.

4. The most attractive method of RTFC is the pole number change. This has the potential to enhance vector control because it would perform the same current decomposition to form a $\mathrm{d}$-axis current pulse that would demagnetize magnet(s) as operation at high speed begins and re-magnetize magnet(s) as high speed operation ceases.

5. We have shown that as the speed of a PM motor increases, the number of turns per coil must be reduced to achieve peak power delivery. Reducing the number of turns per coil is also a method of reducing the back-emf to accomplish RTFC. Additional power as well as higher speed operation is a good combination of benefits.

6. Another attractive method of RTFC is the coil number change which would have to be used in conjunction with the pole number change because the ratio of coils to poles must remain constant. A number of papers have discussed changing the coil number for an induction motor, which automatically induces fewer poles when the number of coils is reduced. For a PM motor, the number of magnet poles may only be reduced by demagnetization.

7. Mechanical RTFC, such as variable-gap control, can work for an axial-gap PM motor, but is much more difficult for a radial-gap motor because of the requirement that the gap be precisely controlled by axial motion of a conical rotor. The usual problem remains of energy expended as the gap is opened and closed to accomplish field weakening.

8. To date, most of the efforts have focused on changing magnetic-flux-flow paths. We feel that the alternatives, which change the magnet properties or number of turns, should be examined for applicability to FreedomCAR HEVs. 


\section{REFERENCES}

1. D. W. Novotny and T. A. Lippo, Vector Control and Dynamics of AC Drives, Clarendon Press, Oxford, 1996 (republished 2000).

2. J. S. Hsu, "Direct Control of Air Gap Flux in Permanent Magnet Machines," Paper No. TR7-001 in IEEE Transactions on Energy Conversions, 2000.

3. J. S. Hsu, Equalized Field Weakening of Permanent Magnet Motors and Generators, Patent \#6,057,622, (Application Number 09/234,919; Disclosure \#1200000605, September 8, 1998 - Filed January 21, 1999), issued May 2, 2000.

4. J. S. Hsu, High Strength Undiffused Brushless Electric Motors and Generators, Patent \#6,573,634 (Application Number 09/872,048; Disclosure \#1300000945, April 12, 2001 Filed June 1, 2001), issued June 3, 2003.

5. V. Ostovic, "Memory Motors - A New Class of Controllable Flux PM Machines for a True Wide Speed Operation," Conf. Record of the 36th IAS Annual Meeting, September 30Octobert 4, 2001.

6. V. Ostovic, "Pole-Changing Permanent Magnet Machines," IEEE Trans. Ind. Applications, 38(6), November/December 2002.

7. Rollin J. Parker, Advances in Permanent Magnetism, A Wiley-Interscience Publication, John Wiley \& Sons, 1990.

8. G. Liang, J. Miller, and X. Xu, "A Vehicle Electric Power Generation System with Improved Output Power and Efficiency," IEEE Trans. on Ind. Applications, 35(6), November/December 1999.

9. S. C. Oh and A. Emadi, "Test and Simulation of Axial Flux-Motor Characteristics for Hybrid Electric Vehicles," IEEE Trans. on Vehicular Technology, 53(3), May 2004.

10. Shigeo Morimoto, "Design, Analyses, and Control of Interior PM Synchronous Machines," Chapter 8 in Tutorial Course Notes, Nicola Bianchi and Thomas M. Jahns, Organizers, IEEE Industry Applications Society, October 2004. 


\section{DISTRIBUTION}

\section{Internal}
1. D. J. Adams
2. C. W. Ayers
3. T. A. Burress
4. S. L. Campbell
5. C. L. Coomer
6. E. C. Fox
7. K. P. Gambrell
8. J. S. Hsu
9. P. A. Jallouk
10. K. T. Lowe
11. L. D. Marlino
12. J. W. McKeever
13. S. C. Nelson
14. M. Olszewski
15. R. H. Wiles
16-17. Laboratory Records

\section{External}

18. T. Q. Duong, U.S. Department of Energy, EE-2G/Forrestal Building, 1000 Independence Avenue, S.W., Washington, D.C. 20585.

19. R. R. Fessler, BIZTEK Consulting, Inc., 820 Roslyn Place, Evanston, Illinois 60201-1724.

20. K. Fiegenschuh, Ford Motor Company, Scientific Research Laboratory, 2101 Village Road, MD-2247, Dearborn, Michigan 48121.

21. V. Garg, Ford Motor Company, 15050 Commerce Drive, North, Dearborn, Michigan 48120-1261.

22. E. Jih, Ford Motor Company, Scientific Research Laboratory, 2101 Village Road, MD1170, Rm. 2331, Dearborn, Michigan 48121.

23. A. Lee, Daimler Chrysler, CIMS 484-08-06, 800 Chrysler Drive, Auburn Hills, Michigan 48326-2757.

24. F. Liang, Ford Motor Company, Scientific Research Laboratory, 2101 Village Road, MD1170, Rm. 2331/SRL, Dearborn, Michigan 48121.

25. M. W. Lloyd, Energetics, Inc., 7164 Columbia Gateway Drive, Columbia, Maryland 21046.

26. Brenda Medellon, USCAR, brenda@uscar.org

27. M. Mehall, Ford Motor Company, Scientific Research Laboratory, 2101 Village Road, MD2247, Rm. 3317, Dearborn, Michigan 48124-2053.

28. J. Rogers, Chemical and Environmental Sciences Laboratory, GM R\&D Center, 30500 Mound Road, Warren, Michigan 48090-9055.

29. S. A. Rogers, U.S. Department of Energy, EE-2G/Forrestal Building, 1000 Independence Avenue, S.W., Washington, D.C. 20585.

30. G. S. Smith, General Motors Advanced Technology Center, 3050 Lomita Boulevard, Torrance, California 90505.

31. E. J. Wall, U.S. Department of Energy, EE-2G/Forrestal Building, 1000 Independence Avenue, S.W., Washington, D.C. 20585.

32. B. Welchko, General Motors Advanced Technology Center, 3050 Lomita Boulevard, Torrance, California 90505.

33. P. G. Yoshida, U.S. Department of Energy, EE-2G/Forrestal Building, 1000 Independence Avenue, S.W., Washington, D.C. 20585. 